\title{
The Italian Society for Rheumatology clinical practice guidelines for rheumatoid arthritis
}

\author{
S. Parisi $i^{1,2}$, A. Bortoluzzi ${ }^{1,3}$, G.D. Sebastiani, ${ }^{4}$, F. Conti ${ }^{5}$, R. Caporali ${ }^{6}$, N. Ughi ${ }^{1,7}$, \\ I. Prevete ${ }^{1,4}$, A. Ariani ${ }^{1,8}$, M. Manara ${ }^{1,7}$, G. Carrara ${ }^{1}$, C.A. Scirè ${ }^{1,3}$ \\ ${ }^{1}$ Epidemiology Research Unit, Italian Society for Rheumatology, Milan, Italy; ${ }^{2}$ Rheumatology Unit, \\ University Hospital, Turin, Italy; ${ }^{3}$ Department of Medical Sciences, Rheumatology Section, \\ University of Ferrara, Italy; ${ }^{4}$ Rheumatology Unit, Azienda Ospedaliera San Camillo-Forlanini, Rome, Italy; \\ ${ }^{5}$ Rheumatology Division, I Clinica Medica, Policlinico Umberto I, Rome, Italy; \\ ${ }^{6}$ Department of Rheumatology, University and IRCCS Foundation Policlinico S. Matteo, Pavia, Italy; \\ ${ }^{7}$ Division of Clinical Rheumatology, Centro Specialistico Ortopedico-Traumatologico \\ Gaetano Pini CTO ASST, Milan, Italy; ${ }^{8}$ Department of Medicine, Internal Medicine \\ and Rheumatology Unit, Azienda Ospedaliero-Universitaria di Parma, Italy
}

\section{SUMMARY}

Rheumatoid arthritis (RA) is a chronic inflammatory autoimmune disorder characterised by chronic joint inflammation, leading to functional disability and increased risk of premature death. Clinical practice guidelines (CPGs) are expected to play a key role in improving management of RA, across the different phases of the disease course. Since new evidence has become available, the Italian Society for Rheumatology (SIR) has been prompted to update the 2011 recommendations on management of RA.

The framework of the Guidelines International Network Adaptation Working Group was adopted to identify, appraise (AGREE II), synthesize, and customize the existing RA CPGs to the Italian healthcare context. The task force consisting of rheumatologists from the SIR Epidemiology Research Unit and a committee with experience in RA identified key health questions to guide a systematic literature review. The target audience includes physicians and health professionals who manage RA in practice, and the target population includes adult patients diagnosed as having RA. An external multi-disciplinary committee rated the final version of the CPGs. From the systematic search in databases (Medline, Embase) and grey literature, 6 CPGs were selected and appraised by two independent raters. Combining evidence and statements from these CPGs and clinical expertise, 8 (Management) +6 (Safety) recommendations were developed and graded according to the level of evidence. The statements and potential impact on clinical practice were discussed and assessed.

These revised recommendations are intended to provide guidance for the management of RA and to disseminate the best evidence-based clinical practices for this disease.

Key words: Clinical practice guidelines, recommendations, rheumatoid arthritis, management, safety.

Reumatismo, 2019; 71 (S1): 22-49

\section{INTRODUCTION}

heumatoid arthritis (RA) is the most common autoimmune inflammatory arthritis in adults (1) and it is characterized by inflammation, pain, stiffness and progressive joint destruction leading to increased morbidity and mortality (2-4). Furthermore, RA is associated with a significant negative impact on the ability to perform daily activities, including work and household tasks, and health-related quality of life $(5,6)$. Though management of RA has strongly improved over the past 30 years, the best therapeutic target has not yet been defined (7). Several treatments for RA are available among disease-modifying antirheumatic drugs (DMARDs), such as conventional synthetic (cs) DMARDs (8), including methotrexate (MTX) (9) and several biological (b) DMARDs. Moreover, the first targeted synthetic (ts) DMARDs (10) have been recently approved for use in RA in Italy. In spite of their efficacy, safety issues raised major concerns in everyday practice and many rheumatologic societies 
developed specific recommendations aiming to stratify and minimize adverse events. In particular, the presence of comorbidities (e.g. cardiovascular disease), the concurrence of infections and host-related risk factors (e.g. hepatotropic virus hepatitis B and $\mathrm{C}$ ), and the possible reactivation of latent tuberculosis infection, strongly affect drug choice and patient monitoring.

The Italian Society for Rheumatology (SIR) issued guidelines on the management and safety of drugs for RA in 2011 $(11,12)$. Since their publication, new scientific evidence concerning management of RA has emerged. Updating high-quality recommendations and Clinical Practice Guidelines (CPGs) in clinical practice requires substantial consumption of time and resources and a great deal of effort to be properly adapted and disseminated in the local context. The ADAPTE methodology, based on already existing guidelines, is a valid alternative to de novo local CPG development $(13,14)$, and it is expected to play a key role in improving management of patients with RA.

\section{NEED FOR ITALIAN GUIDANCE}

The most recent SIR recommendations focusing on the management and safety of patients with RA were published in 2011 (11, 12) and aimed to update EULAR 2010 (15). The increase in standards of care has made management of RA more and more complex. Therefore, recommendations on management of patients with RA are needed to provide physicians, patients, financial backers, regulators and other healthcare suppliers with evidence-based guidance supported by the views of experts. The evidence in terms of efficacy and safety for available drugs has accumulated and new treatment options are available. Finally, several new international guidelines on RA have been published over the last few years $(16,17)$.

\section{Objective}

These CPGs aim to offer revised, evidencebased, and adapted recommendations for the management and safety of patients with RA in Italy.

\section{Target patient population}

Adult patients (age $\geq 18$ years) with clinical diagnosis of RA.

\section{Target users}

Attending physicians (general practitioners, rheumatologists) and health professionals who manage patients with RA in primary care, and hospital and community practice settings. Patients, policy makers and those responsible for commissioning care for patients with RA in the Italian National Health Service (NHS).

\section{What is covered}

These CPGs focus on holistic management of patients with RA.

\section{Areas that are not covered}

Recommendations on surgical management and post-operative rehabilitation of patients with RA are not included in these guidelines.

\section{MATERIALS AND METHODS}

\section{Approach to guideline development}

De novo guideline development is timeconsuming and requires substantial costs (funds, expertise, and human resources). As several RA guidelines have been published by international scientific associations, a systematic approach based on the framework of the Guidelines International Network Adaptation Working Group (http://www.g-i-n.net) following the work of the ADAPTE collaboration $(13,14)$ has been adopted to identify, appraise, synthesize, and customize the existing international guidelines to the needs of the Italian healthcare context.

\section{Assembly of the Working Group}

The Working Group included 10 rheumatologists on behalf of the SIR. Six rheumatologists (N.U., I.P., M.M., A.B, A.A., S.P.), one biostatistician (G.C.) and a project coordinator (C.A.S.) from the SIR Epidemiology Research Unit were responsible for the methodology of development of these CPGs. Three expert clinicians designated by SIR (F.C., R.C., 
G.D.S.) were engaged in each phase of the guideline development by attending a meeting at the $54^{\text {th }}$ SIR National Meeting (November, $22^{\text {nd }}-25^{\text {th }} 2017$ ), contributing to e-mail discussions, and participating in web-meetings (April, 30 $0^{\text {th }}$ and July $10^{\text {th }}$ 2018).

\section{Stakeholder involvement}

The draft of these recommendations has been revised and rated by an external multidisciplinary commission of rheumatologists, a general practitioner, and a representative of patients' associations at the invitation of SIR. The recommendations were developed without any input from, or cooperation with, any pharmaceutical company.

\section{Defining the scope}

A comprehensive list of potential management questions to be addressed was developed a priori and defined by consensus. 16 health questions ( 9 about management and 7 about safety) were identified (Table I) and guided the systematic literature searches.

\section{Inclusion and exclusion criteria}

International CPGs and consensus statements with recommendations for RA endorsed by scientific societies such as SIR, The Italian group for the Study and Management of the Infections in patients with Rheumatic diseases (ISMIR), the American College of Rheumatology (ACR), the European League Against Rheumatism recommendations (EULAR), published

Table I - Key questions regarding the overall management and safety of RA patients.

\begin{tabular}{|c|c|c|}
\hline No. & Text of the health question & No. recommendation \\
\hline \multicolumn{3}{|c|}{ MANAGEMENT QUESTIONS } \\
\hline 1. & When to start therapy for RA? & 1 \\
\hline 2. & What is the initial therapy for the treatment of RA? & $\|$ \\
\hline 3. & What is the role of glucocorticoid therapy? & III \\
\hline 4. & $\begin{array}{l}\text { In case of intolerance or contraindications to the MTX, are there any preferences for another csDMARDs } \\
\text { or bDMARDs? }\end{array}$ & IV \\
\hline 5. & $\begin{array}{l}\text { After how long is it correct to judge the therapy non-optimal (not in remission or in LDA) } \\
\text { and which parameters should be used? }\end{array}$ & NA \\
\hline 6. & What pharmacological treatment after csDMARDs failure? & V \\
\hline 7. & After failure of the first bDMARD, which strategy is preferable? switch or swap? & $\mathrm{VI}$ \\
\hline 8. & After failure of the second or subsequent bDMARD, which strategy is preferable? switch or swap? & VII \\
\hline 9. & $\begin{array}{l}\text { In case of persistent remission, is it possible to reduce or discontinue therapy with bDMARDs } \\
\text { and csDMARDs? }\end{array}$ & VIII \\
\hline \multicolumn{3}{|c|}{ SAFETY QUESTIONS } \\
\hline 1. & $\begin{array}{l}\text { TB: request IGRA and/or TST + RX Chest before starting therapy with bDMARDs, or only IGRA } \\
\text { and proceed with other tests based on the results? Re-check? If so, with what timing? }\end{array}$ & 1 \\
\hline 2. & $\begin{array}{l}\text { Hepatitis B: when to start prophylaxis and with which medication? For how long? When to suspend it? } \\
\text { Which are the indicators for monitoring and which for timing? }\end{array}$ & $\|$ \\
\hline 3. & $\begin{array}{l}\text { Hepatitis C: which patients can be treated with the new therapies available? When to start treatment? } \\
\text { Which are the indicators for monitoring and which for timing? }\end{array}$ & III \\
\hline 4. & CVD: Which strategy to adopt in case of cardiovascular disease? & IV \\
\hline 5. & Which therapeutic strategy to use in patients with previous neoplasia? & V \\
\hline 6. & What are indications and contraindications to vaccinations in patients with RA? & $\mathrm{VI}$ \\
\hline 7. & Which strategy to adopt in case of pregnancy during RA? & NA \\
\hline
\end{tabular}

RA, rheumatoid arthritis; TB, tuberculosis; MTX, methotrexate; csDMARD, conventional synthetic disease-modifying antirheumatic drug; bDMARD, biologic disease-modifying antirheumatic drug; LDA, low disease activity; TST, tuberculosis skin test; IGRA, interferon gamma release assay; CVD, cardiovascular disease; NA, not answered. 
in English or Italian between January $1^{\text {st }}$, 2012, and July $31^{\text {st }} 2017$, were included. Non-international recommendations were considered only if the role of the scientific society was judged relevant.

Reasons for exclusion: study design [randomized controlled trials (RCT) and uncontrolled trials, observational studies, editorials, commentaries, conference abstracts and narrative/systematic reviews]; languages other than English and Italian; poor methodology and reporting; non-original CPGs (i.e. duplication, adaptation or update of previous recommendations) and those not covering any key health questions.

\section{Search strategy}

The strategy was discussed with a member of the SIR Epidemiology Research Unit and the systematic literature search was performed by S.P. in Medline and Embase databases combining keywords for rheumatoid arthritis, guidelines and consensus statements. Furthermore, a grey literature search of rheumatology societies, guideline clearinghouses, cross-references and a gate-keeper (Google Scholar) was performed (Appendix 1). All search results were screened by 2 independent reviewers (S.P., A.B.), and disagreements were resolved by consensus. A flow chart of the results is shown in Figure 1.

\section{Appraisal of guideline quality}

Guideline quality was assessed by two trained raters (S.P., A.B.) using the online Appraisal of Guidelines Research and Evaluation (AGREE) II instrument (18). The AGREE II is made up of 23 items organized into 6 quality domains: scope and purpose, stakeholder involvement, rigor of development, clarity of presentation, applicability, and editorial independence. Upon completing the 23 items, the criteria considered in the assessment process were used to formulate a score and a singleitem overall assessment of the guideline as Recommend (R), Recommend with Provisos $\left(\mathrm{R}^{*}\right)$, or Would Not Recommend. The AGREE assessments were not considered as criteria for exclusion.

\section{Level of evidence and strength of recommendation}

Different grading systems for evidence were used across the CPGs. In order to harmonize these differences, each guideline's grading system was revised and reported rating the level of evidence and strength of recommendation by the Oxford Levels of Evidence (19) (Table II). In case of disagreements, the rating of the recommendation based on the most updated evidence base was considered.

\section{Evidence framework and development of recommendations}

The descriptive characteristics of included CPGs (guideline developer, topic, country, language, publication year, end-of-search date, grading system) and AGREE scores were synthesized. For each key question, evidence tables containing guideline characteristics, recommendations, AGREE summary scores, and level of evidence and strength of recommendation according to the original grading system were prepared. Each recommendation was developed by endorsement or adaptation and reword-

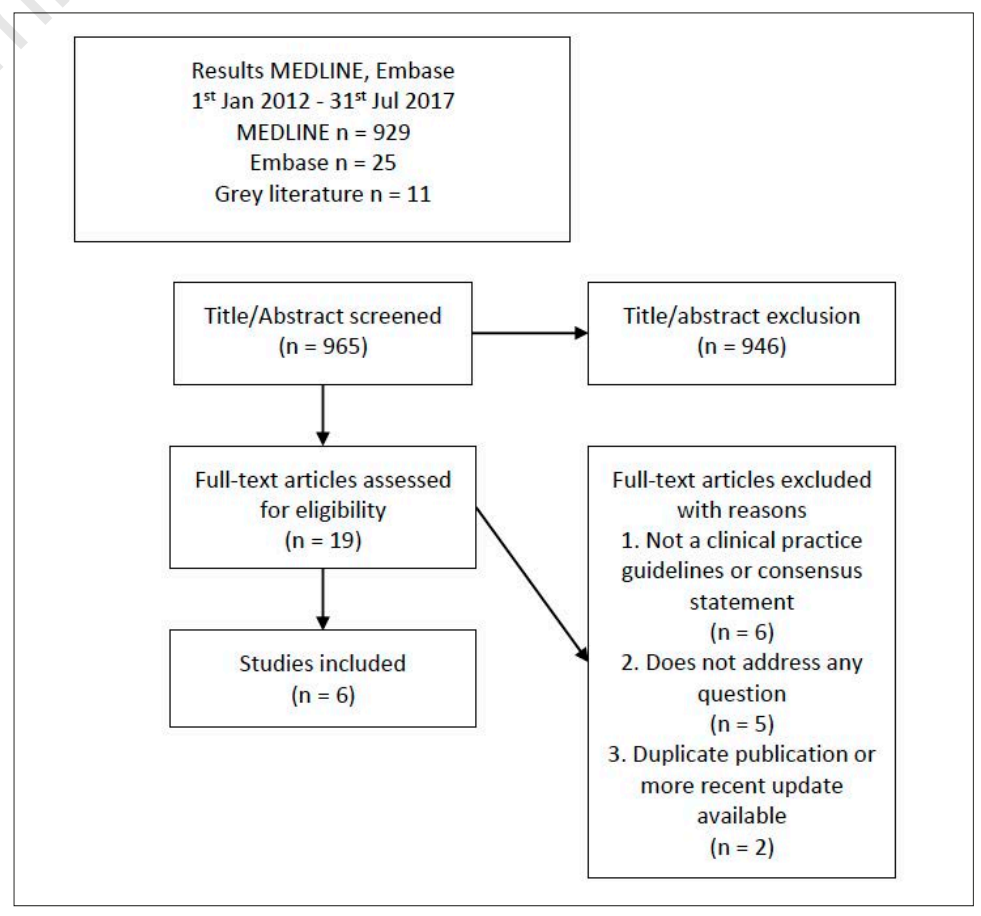

Figure 1 - Steps in the systematic review of guidelines on treatment of rheumatoid arthritis. 
Table II - Guidance to categories of evidence and strength of recommendations based on the Oxford Levels of Evidence (19).

\begin{tabular}{|c|l|}
\hline Level & Evidence \\
\hline 1 & From meta-analysis of randomized controlled trials or from at least one randomized controlled trial \\
\hline 2 & From at least one controlled study without randomization or from at least one cohort study \\
\hline 3 & From at least one case-control study \\
\hline 4 & From case-series or poor-quality cohort and case-control studies \\
\hline 5 & From expert committee reports or opinions and/or clinical experience of respected authorities \\
\hline
\end{tabular}

ing of the existing recommendations. The reporting of these CPG complies with the AGREE reporting checklist (20).

\section{External review}

The draft of the recommendations was sent to external reviewers $(n=14)$ for comment and rating. An online survey was performed via Google Forms between October and November 2018 and feedback from respondents $(n=10$, response rate $71.4 \%)$ was considered to finalize the recommen-

Table III - The choice of treatment is based on disease activity and other patient factors such as comorbidities, safety issues and poor prognostic factors indicated below (162-165).

\begin{tabular}{|l|l|}
\hline \multirow{4}{*}{$\begin{array}{l}\text { Poor prognostic } \\
\text { factors }\end{array}$} & High acute phase reactant levels $(162,163)$ \\
\cline { 2 - 2 } & High swollen joint counts (162-164) \\
\cline { 2 - 2 } & $\begin{array}{l}\text { Presence of RF and/or ACPA, especially at high levels } \\
(162,165)\end{array}$ \\
\cline { 2 - 2 } & Presence of erosions or progressive structural damage (162) \\
\hline
\end{tabular}

RF rheumatoid factor; ACPA, anticitrullinated protein antibody.

Table IV - Disease activity should be categorized as low, moderate, or high as per validated scales based on disease activity indices reported below with the remission or low disease activity criteria (Adapted from ref 166).

\begin{tabular}{|l|l|}
\hline \multirow{3}{*}{$\begin{array}{l}\text { Disease Activity } \\
\text { Indices }\end{array}$} & DAS28 \\
\cline { 2 - 2 } & SDAI \\
\cline { 2 - 2 } & CDAl \\
\hline \multirow{4}{*}{ LDA } & $\begin{array}{l}\text { Low disease activity state according to any } \\
\text { of the validated composite disease activity measures } \\
\text { that include joint counts }\end{array}$ \\
\hline \multirow{3}{*}{$\begin{array}{l}\text { Defined remission } \\
\text { (Boolean } \\
\text { definition) }\end{array}$} & Tender joint count: $\leq 1$ \\
\cline { 2 - 2 } & Swollen joint count: $\leq 1$ \\
\cline { 2 - 2 } & C-reactive protein level (mg/dl): $\leq 1$ \\
\cline { 2 - 2 } & Patient global assessment $\leq 1$ \\
\hline
\end{tabular}

DAS28, Disease Activity Score 28 joints; SDAI, Simplified Disease Activity Index; CDAl, Clinical Disease Activity Index; LDA, Low Disease Activity. dations. The results of the external review are provided as supplementary material (Appendix 2).

\section{RESULTS}

\section{Key to understanding these guidelines}

Each recommendation is presented with a level of evidence and strength and is accompanied by supporting text that is structured as follows:

Overarching Principles. Presentation of general principles for the treatment of patients with RA as overarching.

Recommendation. The final statement of SIR.

Summary of guidelines. A synthesis of recommendations made by RA guidelines identified from the systematic review.

Recommendation/supporting evidence. Specific source guidelines that were used for adaptation.

Evidence for recommendation. Results of the panel discussion of the adapted recommendation with regard to further specifications and comments on the sources used to develop the recommendation.

\section{Overarching principles}

The aim of the RA treatment should be the best care of the patient. It must be based on a shared decision between the patient and the rheumatologist who is the specialist who should primarily care for patients with RA. This principle remained confirmed also in these guidelines. The target of clinicians is remission or low disease activity, with long-lasting effect and with as little pharmacological treatment as possible. Thus, prognostic factors (Table III), further to disease du- 
Table V - Disease Activity Index Range (Adapted from Ref. 166).

\begin{tabular}{|l|c|c|c|}
\hline Reference Values & DAS28 (ESR) & SDAl & CDAl \\
\hline Remission & $<2.6$ & $\leq 3.3$ & $\leq 2.8$ \\
\hline Low & $\geq 2.6 \mathrm{e}<3.2$ & $\geq 3.4 \mathrm{e} \leq 11$ & $>2.8 \mathrm{e} \leq 10$ \\
\hline Moderate & $\geq 3.2 \mathrm{e} \leq 5.1$ & $>11 \mathrm{e} \leq 26$ & $>10 \mathrm{e} \leq 22$ \\
\hline High & $>5.1$ & $>26$ & $>22$ \\
\hline
\end{tabular}

DAS28, Disease Activity Score 28 joints; ESR, Erythrocyte sedimentation rate; SDAI, Simplified Disease Activity Index; CDAl, Clinical Disease Activity Index.

ration, should be importantly taken into account (21).

Treatment decisions should be guided by disease activity as well as by comorbidities and safety issues. It is suggested that disease activity be categorized as low, moderate, or high as per validated scales based on the indices reported in Tables IV and V.

\section{Recommendations}

6 original CPGs $(16,17,22-25)$ were selected and used to accomplish the final first set of 8 recommendations on management (Table VI) and the second set of 6 recommendations on safety (Table VII). An algorithm which summarizes the pathway for the treatment strategy of patients with RA is shown in Figure 2. Glossary and definitions are presented in Appendix 3.

\section{FIRST SET \\ MANAGEMENT}

\section{RECOMMENDATION 1}

Treatment with csDMARDs should be started as soon as the diagnosis of RA is made. $(1, \mathrm{~A})$.

(Level 1; Strength A)

Summary of guidelines. The search identified 2 CPGs that addressed the optimal management of RA. Both CPGs recommend clinicians to start therapy with csDMARDs as soon as possible in RA.

Recommendation/supporting evidence. EULAR 2016 (16) and ACR 2015 (17).

Evidence for recommendation. The panel agreed upon the importance of early treatment at diagnosis. It is now widely recognized that early treatment enables prevention of damage to most patients with RA (26).

\section{RECOMMENDATION 2}

MTX should be part of the first treatment strategy. (1, A).

(Level 1; Strength A)

Summary of guidelines. The search identified 2 CPGs that addressed the optimal management of RA. According to EULAR and ACR recommendations, clinicians should start therapy with MTX as soon as the diagnosis of RA is defined.

Recommendation/supporting evidence. EULAR 2016 (16) and ACR 2015 (17).

Evidence for recommendation. The panel agreed upon the role of MTX as the first treatment strategy at diagnosis. MTX continues to be the anchor drug for RA patients both in monotherapy and in combination with other drugs. Furthermore, robust data indicate that MTX has a positive impact on morbidity and mortality in RA $(27,28)$.

\section{RECOMMENDATION 3}

A short-term course of glucocorticoids can be considered to control active RA in combination with csDMARDs. In view of their cumulative side effects, they should be used at the lowest dose necessary and tapered as rapidly as clinically feasible $(<6$ months).

Intra-articular glucocorticoid injections should be considered for the relief of local symptoms of inflammation. (1, A).

(Level 1; Strength A) 
Summary of guidelines. The search identified 2 CPGs that addressed optimal management of GC in RA. According to the EULAR recommendations, clinicians should use glucocorticoids when initiating or switching csDMARDs, in different dose regimens and routes of administration, but they should be tapered as rapidly as clinically feasible, considering the long-term side effects.

Recommendation/supporting evidence. EULAR 2016 (16), EULAR early 2016 (22).

Evidence for recommendation. The panel agreed with the concept of short-term instead of low-dose. Moreover, intra-articular steroids may be considered to improve joint symptoms (in association with DMARDs) especially in patients with early arthritis (29).

\section{RECOMMENDATION 4}

In patients with a contraindication or intolerance to MTX, leflunomide or sulfasalazine should be considered as part of the (first) treatment strategy. (1, A).

(Level 1; Strength A)

Summary of guidelines. The search identified 1 CPGs that addressed optimal management of csDMARDs in RA.

Recommendation/supporting evidence. EULAR 2016 (16).

Evidence for recommendation. According to EULAR 2016, clinicians should start therapy with leflunomide (LFN) or Sulfasalazine (SSZ) in selected RA patients, since they have proved to be efficacious $(30,31)$. As for MTX, also in this treatment strategy the panel means the use of LFN and SSZ in monotherapy or in combination with other bDMARDs (32-35). Compared to the other csDMARDs, hydroxychloroquine, although still used, especially in the forms of mild RA, does not delay the articular damage, therefore it has not been included (36).

\section{RECOMMENDATION 5}

- If the treatment target is not achieved with a csDMARD strategy, in the ab- sence of poor prognostic factors, other csDMARDs should be considered.*

- If the treatment target is not achieved with the first csDMARD strategy, when poor prognostic factors are present, addition of a bDMARD ${ }^{\dagger}$ or a tsDMARD should be considered (add a TNF-i or a non-TNF-i or JAK-i without any order of preference).*

$*(5, \mathrm{D}){ }^{\dagger}(1, \mathrm{~A})$. (Level 1-5; Strength A-D)

Summary of guidelines. The search identified 2 CPGs that addressed optimal management of DMARDs in RA. According to ACR and EULAR, clinicians should add another csDMARD in the absence of poor prognostic factors. On the other hand, clinicians should consider adding bDMARD or tsDMARD when poor prognostic factors are present (Table III).

Recommendation/supporting evidence. EULAR 2016 (16), ACR 2015 (17).

Evidence for recommendation. The panel agreed not to indicate any hierarchical position in the bDMARDs or tsDMARDs (16, 37-39). Considering the availability of biosimilars, these should be preferred to originators for cost reasons $(16,40-42)$. Furthermore, the panel decided to include the tsDMARDs (Janus Kinase inhibitors, JAK-i) in this recommendation following trials on the efficacy and safety of tofacitinib and baricitinib, both already approved in Italy (43). With patients who cannot use csDMARDs as comedication, IL-6 pathway inhibitors and tsDMARDs (Baricitinib) may have some advantage compared with other bDMARDs. However, the panel preferred not to recommend it due to the lack of consistent evidence (44-46).

\section{RECOMMENDATION 6}

If a bDMARD has failed, treatment with another bDMARD or a tsDMARD should be considered; if one TNF-i therapy has failed, patients may receive another TNF-i or an agent with another mode of action. $(5, \mathrm{D})$.

(Level 5; Strength D) 
Summary of guidelines. The search identified 2 CPGs that addressed optimal management of bDMARDs in RA. One CPG (17) recommended changing the mechanism of action upon failure of TNF-inhibitors (TNF-i), while the other recommended the change of therapy irrespective of the mechanism of action (16).

Recommendation/supporting evidence. EULAR 2016 (16), ACR 2015 (17)

Evidence for recommendation. Clinicians should consider another bDMARD or tsDMARD when the first bDMARD has failed without any preference between TNF-i or other mechanism of action. The panel agreed upon the importance of considering another strategy with bDMARD or tsDMARD when the first treatment has failed according to a cycling or switch strategy. The panel preferred this solution considering prospective studies and meta-analysis which showed no differences between the two approaches (47-49).

\section{RECOMMENDATION 7}

Patients who fail to achieve remission or low disease activity with a second bDMARD therapy are recommended to switch to another bDMARD or a tsDMARD. If

Table VI - Final set of Recommendations on treatment strategy in RA (Management).

\begin{tabular}{|c|c|c|c|}
\hline No. & $\begin{array}{l}\text { The final set of "Management" } \\
\text { Recommendations }\end{array}$ & $\begin{array}{l}\text { Category } \\
\text { of Evidence }\end{array}$ & $\begin{array}{l}\text { Grade of } \\
\text { Recommendation }\end{array}$ \\
\hline 1 & Treatment with csDMARDs should be started as soon as the diagnosis of RA is made. & 1 & A \\
\hline 2 & MTX should be part of the first treatment strategy. & 1 & A \\
\hline 3 & $\begin{array}{l}\text { Short-term course of glucocorticoids can be considered to control active RA } \\
\text { in combination with csDMARDs. In view of their cumulative side effects, they should } \\
\text { be used at the lowest dose necessary and tapered as rapidly as clinically feasible } \\
\text { ( } 66 \text { months). } \\
\text { Intra-articular glucocorticoid injections should be considered for the relief of local } \\
\text { symptoms of inflammation. }\end{array}$ & 1 & A \\
\hline 4 & $\begin{array}{l}\text { In patients with a contraindication or intolerance to MTX, LFN or SSZ should } \\
\text { be considered as part of the (first) treatment strategy. }\end{array}$ & 1 & A \\
\hline 5 & $\begin{array}{l}\text { If the treatment target is not achieved with a csDMARD strategy, in the absence } \\
\text { of poor prognostic factors, other csDMARDs should be considered*. } \\
\text { If the treatment target is not achieved with the first csDMARD strategy, when poor } \\
\text { prognostic factors are present, addition of a bDMARD }{ }^{\dagger} \text { or a tsDMARD should be } \\
\text { considered (add a TNF-i or a non-TNF-i or JAK-i without any particular order of } \\
\text { preference).* }\end{array}$ & $5^{\star}$ & $\mathrm{D}^{\star}$ \\
\hline 6 & $\begin{array}{l}\text { If a bDMARD has failed, treatment with another bDMARD or a tsDMARD should } \\
\text { be considered; if one TNF-i therapy has failed, patients may receive another TNF-i } \\
\text { or an agent with another mode of action. }\end{array}$ & 5 & $\mathrm{D}$ \\
\hline 7 & $\begin{array}{l}\text { Patients who fail to achieve remission or low disease activity with a second bDMARD } \\
\text { therapy are recommended to switch to another bDMARD agent or a tsDMARD. } \\
\text { If the second bDMARD failure is TNF-i: use another bDMARD (non-TNF-i) } \\
\text { or a tsDMARD with or without MTX. }\end{array}$ & 5 & D \\
\hline 8 & $\begin{array}{l}\text { If a patient is in sustained remission, a reduction in treatment should be considered. } \\
\text { - bDMARDs or tsDMARDs tapering, especially if this treatment is combined } \\
\text { with a csDMARDs, could be considered. }{ }^{*} \\
\text { - csDMARDs tapering could be considered. }{ }^{\dagger}\end{array}$ & $4^{\dagger}$ & $\mathrm{B}^{\star}$ \\
\hline
\end{tabular}

RA, Rheumatoid Arthritis; MTX, Methotrexate; LFN, Leflunomide; SSZ, sulfasalazine; csDMARD, conventional synthetic diseasemodifying antirheumatic drug; bDMARD, biologic disease-modifying antirheumatic drug; tsDMARD, target synthetic disease-modifying antirheumatic drug; TNF-i, Tumor Necrosis Factor inhibitor; JAK-i, janus kinase inhibitor.

The symbols $\left({ }^{*},{ }^{\dagger}\right)$ relate to the corresponding symbols in the recommendations, showing in the respective grade. 
the second bDMARD failure is TNF-i: use another bDMARD (non-TNF-i) or a tsDMARD with or without MTX. (5, D).

(Level 5; Strength D)

Summary of guidelines. The search identified 2 CPGs that addressed optimal management of bDMARDs failure in RA. According to ACR and EULAR recommendations, clinicians should consider another bDMARD or tsDMARD when another bDMARD has failed, preferring another mechanism of action (non-TNF-i or tsDMARD).

Recommendation/supporting evidence. EULAR 2016 (16), ACR 2015 (17)

Evidence for recommendation. Although the evidence is of very low quality, especially for tsDMARDs (50-54), the panel agreed upon the importance of considering another strategy with bDMARDs or tsDMARDs when the other treatment has failed according to swap strategy. Furthermore, it is specified for clarity that the combination therapy with MTX should be always maintained where possible.

\section{RECOMMENDATION 8}

If a patient is in sustained remission, a reduction in treatment should be considered.

- bDMARDs or tsDMARDs tapering, especially if this treatment is combined with a csDMARDs, could be considered*

- csDMARDs tapering could be considered $^{\dagger}$

$*(2, \text { B })^{\dagger}(4$, C). (Level 2-4; Strength B-C)

Summary of guidelines. The search identified 2 CPGs that addressed optimal management of RA therapy. According to ACR and EULAR, clinicians should consider tapering of bDMARDs or tsDMARDs when the patient is in sustained remission ( $\geq 12$ months). The tapering of csDMARDs should be subsequently considered, as well. One CPG highlighted the concept of remission to be understood after steroid tapering (16).

Recommendation/supporting evidence. EULAR 2016 (16), ACR 2015 (17)
Evidence for recommendation. The panel agreed upon the importance of achieving remission without glucocorticoid, because it is fundamental to take into consideration the tapering of the treatment (bDMARD, tsDMARD and csDMARD). Tapering is understood as reduction of the dose or extension of interval between drug administrations (i.e. spacing). The panel also agreed that the recommendation implies tapering until possible interruption of the bDMARD first, if in combination with the csDMARD; tapering of csDMARDs should be considered after the withdrawal of the bDMARD; on the other hand, tapering and stopping bDMARD monotherapy has not yet been studied.

\section{SECOND SET SAFETY TUBERCULOSIS (TB)}

\section{RECOMMENDATION 1}

Screening for active TB or Latent TB is recommended prior to starting bDMARD or tsDMARD therapy. Initial Tuberculosis Skin Test (TST) or Interferon Gamma Release Assay (IGRA) is recommended. IGRA is preferred if the patient has a history of Bacillus Calmette-Guérin (BCG) vaccination.*

a) Patients with a positive initial or repeat TST or IGRA should have a chest radiograph and, if positive for past TB exposure or active $\mathrm{TB}$, a subsequent sputum examination to check for the presence of active TB.*

b) Patients with a negative screening TST or IGRA may not need further workup in the absence of risk factors and/or clinical suspicion for TB.*

c) If the RA patient has active or latent TB based on the test results the panel recommends appropriate anti-tubercular treatment and consideration for referral to a specialist. ${ }^{\dagger}$

d) Treatment with tsDMARDs or bDMARDs can be initiated or resumed after 1 month of latent TB treatment with anti-tubercular medications and after completion of the treatment of active $\mathrm{TB}$, if applicable according to the refer- 
ence specialist (pulmonologist or infectious disease specialist).*

e) Annual testing is recommended in RA patients who live, travel or work in situations where TB exposure is likely while they continue treatment with bDMARDs or tsDMARDs.*

Risk factors for TB exposure: close contacts of persons known or suspected to have active tuberculosis; foreign born persons from areas that have a high incidence of active TB (e.g. Africa, Asia, Eastern Europe, Latin America, and Russia); persons who visit areas with a high prevalence of active TB (especially if visits are frequent or prolonged); residents and employees of congregate settings whose clients are at increased risk for active TB.

$*(2, \mathrm{C}) \dagger(2, \mathrm{~B})$ (Level 2; Strength B-C)

Summary of guidelines. The search identified 2 CPGs that addressed optimal screening and monitoring for active or latent TB in RA patients. The ACR 2015 guidelines modified the ACR 2012 by including tofacitinib in the screening.

Recommendation/supporting evidence. ACR 2015 (17), ACR 2012 (24).

Evidence for recommendation. The Panel, according to the ACR 2012 and 2015 Guidelines, recommends screening to identify latent or active tuberculosis infection in all RA patients being considered for therapy with bDMARDs and tsDMARDs, regardless of the presence of risk factors (55). Since patients with RA may have false-negative tuberculin skin test (TST) or interferon gamma release assay (IGRA) results due to immunosuppression, a negative TST or IGRA should not be interpreted as excluding the possibility that patient has LTBI. Patients who test positive for TST or IGRA at baseline are expected to remain positive for these tests even after successful treatment of active or latent TB. These patient need monitoring for clinical signs and symptoms of recurrent TB, since repeating tests will not help in diagnosis of recurrent TB. In immunosuppressed RA patients with risk factors for TB and negative initial screening tests, a repeat TST or IGRA could be considered 1-3 weeks after the initial negative screening.
The Panel indicated that in the absence of significant new knowledge, development of an alternate recommendation was not warranted with one exception, that the same TB screening algorithm as described for bDMARDs should be followed for patients receiving tsDMARDs. $(56,57)$.

Data from clinical trials seem to indicate increased risk of $\mathrm{TB}$ reactivation in patients treated with TNF-i agents with respect to non-TNF-i. This seems to confirm the class effect resulting from TNF inhibition, which leads to impaired TB granuloma formation (58). The Panel therefore recommends individualizing the choice of therapy in accordance with the respective drug-related risk (59). The data for Italy come from the TB notification system of the Ministry of Health and constitute the official information flow, which is referred to for monitoring the progress of the disease in Italy. The current epidemiological situation of TB in Italy is characterized by a low incidence in the general population, and by the concentration of cases in some groups at risk and in some age groups. In fact, since 2009 there has been a steady increase in the proportion of cases notified among citizens born abroad (44\% in 2005 and $66 \%$ in 2014) (60). The most recent data relating to Italy are published in the joint ECDC document and WHO Europe "Tuberculosis surveillance and monitoring in Europe 2018" and confirm that Italy is one of the countries with low disease incidence $(<20 / 100,000)$ (60). After completion of the treatment of active TB, treatment with bDMARDs or tsDMARDs can be initiated or resumed and the panel suggests that a joint decision with the reference pulmonologist or infectious disease specialist should be taken.

\section{RECOMMENDATION 2}

\section{$H B V$ infection}

a) All RA patients should be screened for HBsAg, antiHBsAb and antiHBcAb, especially before starting bDMARDs or tsDMARDs.*

b) AntiHBcAb positive and HBsAg negative patients should undergo further evaluations, including HBV DNA and 
liver function tests, before starting immunosuppressive therapy. RA treatment should be the same as that of unexposed patients, as long as the patient's viral load is monitored regularly, every 6-12 months.*

c) HBsAg positive patients should undergo further assessments, including quantitative $\mathrm{HBsAg}, \mathrm{HBeAg}$, antiHBe, HBV DNA and anti HDV IgG and liver function tests, before starting immunosuppressive therapy. ${ }^{\dagger}$

d) Active HBV carriers should be referred to the specialist to receive treatment with entecavir or tenofovir, in accordance with the international guidelines, before starting immunosuppressive therapy. ${ }^{\dagger}$

e) Acute HBV infection occurring in patients with RA, such as asymptomatic infections occurring in patients previously negative for $\mathrm{HBV}$ serology, should receive antiviral treatment according to international guidelines. ${ }^{\S}$

f) In inactive $\mathrm{HBV}$ carriers, prophylaxis should be started 4 weeks before the immunosuppressive therapy and continued for 12 months after its discontinuation (24 months in the case of patients treated with rituximab).*

g) Patients stopping prophylaxis should be closely monitored.

$*(2, \mathrm{~B}) .{ }^{\dagger}(1, \mathrm{~A}) .{ }^{\S}(5, \mathrm{~B}) .{ }^{\ddagger}(5, \mathrm{C})$. (Level 1-5; Strength A-C)

Summary of guidelines. The search identified 2 CPGs that addressed optimal screening and monitoring of $\mathrm{HBV}$ in RA patients. Both guidelines emphasize the importance of screening for the diagnosis of RA and of paying special attention to monitoring of HBV carriers.

Recommendation/supporting evidence. ACR 2015 (17), ISMIR 2017 (25).

Evidence for recommendation. ACR 2015 guidelines suggest that immunosuppressive therapy can be safely administered when prophylactic antiviral therapy is concomitantly prescribed $(61,62)$. This recommendation is strong despite very low evidence (61-68). The panel supported the view that the reactivation of HBV infection needs to be carefully considered in RA patients on immunosuppressive therapy, though it is relatively infrequently reported $(69,70)$. A serological screening for $\mathrm{HBV}$ at the time of diagnosis of RA is now universally accepted and strongly recommended (71). Furthermore, no significant differences in the risk of reactivation of overt or occult HBV infections was found among the different bDMARDs, except for rituximab, which presents a higher risk. Thus, an RA patient with natural immunity from prior exposure to HBV infection (i.e., hepatitis B core [HB$\mathrm{cAb}$ ] antibody positive and hepatitis B surface [HBsAb] antibody positive and $\mathrm{HBs}$ antigen [HBsAg] negative), should undergo further evaluations, including HBV DNA and liver function tests (AST, ALT, bilirubin, GGT, albumin, creatinine, INR and a complete cell blood count). In these patients the RA treatment should not be different than with unexposed patients, provided that the viral load is monitored every 6-12 months $(72,73)$. Even in HBsAg positive patients it is necessary to investigate further, both for the infection (quantitative $\mathrm{HBsAg}, \mathrm{HBeAg}$, antiHBe, HBV DNA and anti HDV IgG), and for the liver function (AST, ALT, bilirubin, GGT, albumin, creatinine, INR and a complete cell blood count) (71-73). For patients with chronic HBV infection who are untreated, referral for antiviral therapy is appropriate prior to immunosuppressive therapy $(64,74-80)$.

There are no indications for starting antiviral treatment in occult HBV carriers who are candidates for bDMARDs or tsDMARDs, except for rituximab, where antiviral treatment is suggested (25). The frequency of monitoring HBV DNA levels, in patients not receiving antiviral prophylaxis, can range from one to three months depending on the type of immunosuppressive therapy administered (e.g. combination with csDMARDs or glucocorticoids) (81-84).

\section{RECOMMENDATION 3}

\section{HCV infection}

a) All RA patients should be screened for $\mathrm{HCV}$ infection, especially before starting bDMARDs or tsDMARDs*. 
b) RA patients with $\mathrm{HCV}$ infection should undergo gastroenterological / infectious evaluation for any anti-viral eradicative therapy and should not be treated differently from patients with RA without $\mathrm{HCV}$ infection. ${ }^{\dagger}$

$*(2, \mathrm{~B}){ }^{\dagger}(5, \mathrm{D})$; (Level 2-5; Strength B-D)

Summary of guidelines. The search identified $1 \mathrm{CPG}$ that addressed optimal screening and monitoring of $\mathrm{HCV}$ infection in RA patients. The evidence for this recommendation is very low and based on 2 RCT and small observational studies (85-96), although there is no correlation between TNF-I or MTX therapy and increased viral load in RA patients not treated with anti-viral therapy (91).

Recommendation/supporting evidence. ACR 2015 (17).

Evidence for recommendation. The panel recommended that rheumatologists collaborate with gastroenterologists and infective disease specialists to monitor these patients. HCV RNA levels may increase during immunosuppressive therapies, but without clinically significant hepatitis (97). Immunosuppressive therapies do not seem to have a detrimental effect on the course of HCV infection. This is important considering the recent availability of highly effective anti-viral therapy for HCV (Direct Acting Antiviral drugs), the experience of which in RA is still limited (98).

\section{RECOMMENDATION 4}

\section{Cardiovascular disease (CVD)}

a) CVD risk assessment is recommended for all patients with RA at least once every 5 years and should be reconsidered following major changes in antirheumatic therapy. CVD risk estimation for patients with RA should be performed according to national guidelines and the SCORE CVD risk prediction model should be used if no national guideline is available.*

b) CVD risk prediction models should be adapted for patients with RA by a 1.5 multiplication factor, if this is not already included in the model.*

c) Screening for asymptomatic atheroscle- rotic plaques by use of carotid ultrasound may be considered as part of the CVD risk evaluation in patients with RA.*

e) Lifestyle recommendations should emphasize the benefits of a healthy diet, regular exercise and giving up smoking for all patients. ${ }^{\dagger}$

e) In CVD risk management, antihypertensives and statins may be used as in the general population.*

f) Prescription of Non Steroidal Anti Inflammatory Drugs (NSAIDs) in RA should be made with caution, especially for patients with documented CVD or in the presence of CVD risk factors. ${ }^{\S}$

g) In case of Congestive Heart Failure: use combinations of csDMARDs or non TNF-i or tsDMARDs rather than TNF-i. ${ }^{\dagger}$

h) Congestive Heart Failure worsening on current TNF-i therapy: use combinations of csDMARDs or non TNF-i or tsDMARDs rather than TNF-i.*

i) A TNF-i should only be used if there are no other reasonable options, and then, perhaps, only in compensated heart failure.*

$*(4, \mathrm{D}){ }^{\dagger}(3, \mathrm{C}) .{ }^{\S}(2, \mathrm{~A})$. (Level 2-4; Strength A-D)

Summary of guidelines. The search identified 2 CPGs that addressed optimal management of RA with Cardiovascular Diseases (CVD). According to the EULAR recommendations, in order to optimize treatment for patients with RA and CV risk, an accurate $\mathrm{CV}$ assessment is required. Evaluation of $\mathrm{CV}$ risk in RA patients should be assured once every 5 years if the risk varies from low to moderate (99), or more often for patients with intermediate to high risk, although the Systematic Coronary Risk Evaluation (SCORE) (100) has not yet been validated in AR. The risk prediction models available for the general population have been shown to underestimate $\mathrm{CV}$ risk in patients with RA (101), so many attempts have been made to produce RA-specific risk calculators $(101,102)$. Otherwise, correction factors were suggested $(99,102,103)$. The addition of a multiplication factor of 1.5 to the scoring system in patients with RA was approved by EULAR for implementation in 
daily clinical practice. The correction must be applied regardless of the criteria related to the disease, although high activity and duration of the disease, the presence of rheumatoid factor (RF) and/or anticitrullinated protein antibodies (ACPA) and extra-articular manifestations deserve attention (104, 105). The 2015 ACR guidelines state that the use of TNF-i is allowed in patients with CV comorbidities, but the evidence for recommendation is of very low quality. In the case of heart failure of the New York Heart Association (NYHA) III/IV class, such drugs are to be used with caution due to the risk of worsening heart failure $(106,107)$. The long-term use of non-selective NSAIDs/ COX2 Inhibitors (COXIBs) has been associated with an increased risk of CV (108) Diclofenac is contraindicated in patients with CVD documented and recently some data support similar restrictions for the use of ibuprofen $(109,110)$. Naproxen seems to have the safest CVD risk profile $(108,111)$. Recommendation/supporting evidence. ACR 2015 (17), EULAR 2015 (23).

Evidence for recommendation. Regarding treatment with glucocorticoids, daily use, cumulative dose and duration of treatment are associated with a high CV risk $(108,112$, 113 ) but evidence is not conclusive. However, in accordance with the EULAR recommendations on the management of therapy with glucocorticoids (114), the panel refers to the previously expressed statement based on the concept of short-term therapy with GC. The Panel confirmed that with regard to CVD risk, MTX remains the reference drug $(113,114)$. Non-TNF-i have been shown to have a good safety profile from a CV risk perspective. Both rituximab and tocilizumab have been shown to reduce CVD markers (e.g. lipid panel and carotid intima-medial thickness) (116-119). Abatacept, on the other hand, showed a good safety profile compared to TNF- $i$ in patients with dilated cardiomyopathy (120). Furthermore, the Panel decided to include tsDMARDs, because the available data show a favorable safety profile regarding $\mathrm{CV}$ events (CV death and non-fatal CV events) and congestive heart failure, even though the quality of evidence is still insufficient $(121,122)$.

\section{RECOMMENDATION 5}

\section{Malignancy}

If the disease is moderately or highly active in the setting of a low-grade melanoma or non-melanoma skin cancer that had been previously treated, bDMARDs/ tsDMARDs would be an acceptable option with close skin surveillance in conjunction with a dermatologist.*

a) In general

- use csDMARDs rather than tsDMARDs or bDMARDs.*

b) Previously treated lymphoproliferative disorders:

- use Rituximab over TNF-i ${ }^{\dagger}$

- use combinations of csDMARDs or Abatacept or Tocilizumab rather than TNF-i.*

c) Previously treated solid organ malignancy

- same recommendations as in patients without this condition (in the absence of active malignancy, according to the reference specialist).*

$*(5, \mathrm{D}){ }^{\dagger}(5, \mathrm{C})$ (Level 5; Strength C-D)

Summary of guidelines. The search identified 1 CPG that addressed optimal management of RA patients and malignancy. ACR 2015 CPGs considered csDMARDs less immunosuppressive than bDMARDs and tsDMARDs. The recommendation concerning melanoma and non-melanoma skin cancer is conditional for the very lowquality of the evidence based on clinical experience and the paucity of retrospective studies $(123,124)$. The ACR 2015 recommendation concerning previously treated lymphoproliferative disorders is strongly in favor of rituximab despite very low quality evidence, since rituximab is an approved treatment for some of these disorders. On the other hand, several clinical trial data suggest that there is an increased risk of lymphoma in patients treated with TNF-i, but not with combinations of csDMARDs, abatacept or tocilizumab $(124,125)$.

Recommendation/supporting evidence. ACR 2015 (17).

Evidence for recommendation. Though bDMARDs/tsDMARDs are not the first 
option, the panel indicated that, if RA disease activity is moderate or high in the context of a low-grade melanoma or non-melanoma skin cancer, bDMARDs/tsDMARDs would be an acceptable option with close skin surveillance in conjunction with a dermatologist. Moreover, a recent large European collaborative project did not confirm an overall increased risk of melanoma following exposure to TNF-i (126).

Another important point to emphasize is that immunotherapy has dramatically transformed the prognosis of several cancers (e.g. metastatic melanoma and nonsmall cell lung cancer). Ipilimumab, an immune checkpoint inhibitor targeting cytotoxic T-lymphocyte-associated protein 4 (CTLA-4), has been approved by the US Food and Drug Administration and European Medicines Agency for treating metastatic melanoma $(127,128)$. CTLA-4 is a target of both autoimmunity and cancer. Drugs inhibiting this immune checkpoint have been developed for cancer (ipilimum$a b)$ and drugs activating this inhibitory signal have been developed for autoimmunity (abatacept). Even if no signal for a possible increased risk of cancer has been described with abatacept, the development of RA or other types of adverse events with immune checkpoint inhibitors therapy is an important warning to rheumatologists (129). Long-term studies need to be continued in real-life patients receiving immunosuppressive drugs in general, to be sure there is no increased risk of cancer with time.

Regarding tsDMARDs, no increased risk of malignancy has been reported with tofacitinib in RA; however, experience is limited and this risk must be evaluated in the long term with all JAK-i (130).

Collaboration between rheumatologists and oncologists is crucial and could lead to better recognition and care of these patients.

\section{RECOMMENDATION 6}

\section{Vaccination}

a) Ideally administration of all vaccines, if indicated, should be undertaken at least 4 weeks before starting a tsDMARD or bDMARD.* b) Concurrent administration of live, attenuated vaccines is an absolute contraindication for patients being treated with bDMARDs or tsDMARDs.*

c) Killed vaccines (Pneumococcal, Influenza $^{\wedge}$, Hepatitis B) are recommended, before initiating or during therapy with csDMARDs, tsDMARDs, bDMARDs, in RA patients. (^every year according to epidemiology). ${ }^{\dagger}$

d) Recombinant Vaccine (Human Papilloma) is recommended before initiating or during therapy with csDMARDs, tsDMARDs, bDMARDs in RA patients (according to National Recommendations).*

$*(4, \mathrm{D}) \dagger(1, \mathrm{~A})$. (Level 1-4; Strength A-D)

Summary of guidelines. The search identified 1 CPG that addressed optimal management of vaccination in RA patients. ACR 2015 guidelines support use of killed, recombinant and live attenuated vaccines before initiating therapy, but do not recommend the live attenuated vaccines (Herpes Zoster) during the therapy. All these recommendations have a low grade, except those on killed vaccines, because the evidence is of very low quality (131-145), and there is a safety warning about the use of live vaccines in patients receiving bDMARDs/tsDMARDs $(132,133)$.

Recommendation/supporting evidence. ACR 2015 (17).

Evidence for recommendation. The panel agreed to endorse the same recommendations. Moreover, responses to some killed vaccines may be reduced after rituximab therapy (141) and possibly after MTX therapy.

In the recent study, among patients newly starting tofacitinib, the results highlight that tofacitinib can diminish pneumococcal vaccine immunogenicity to a similar extent as MTX, particularly when these two DMARDs are used concomitantly, whilst influenza responses are affected minimally (146).

Whenever possible, vaccines should be given prior to receiving therapy, and the Panel decided to consider both bDMARDs and tsDMARDs (130). 


\section{Pregnancy}

In the absence of a recommendation on pregnancy in RA, the EULAR points to consider for use of antirheumatic drugs before pregnancy, and during pregnancy and lactation by Götestam Skorpen et al., should be considered as reference (147).

Recently the European Medicines Agency has approved a modification to the data sheet and package leaflet of certolizumab pegol which makes it the first TNF-i that could be used in women suffering from chronic inflammatory diseases before and during pregnancy and breastfeeding (148). The approval of the modification of the data sheet and the package leaflet of certolizumab pegol is based on the collected post-marketing data, the CRIB (149) and CRADLE (150) studies and on the analysis of pregnancy outcome data.

\section{DISCUSSION}

These recommendations contain substantial updates from previous SIR 2011 guidelines on RA. The ADAPTE collaboration methodology was adopted in this project and a complete CPG adapted to the national context was developed through the selected CPGs $(16,17,22-25)$. A first part of the strategy was developed in the algorithm of treatment of RA and a second part was dedicated to safety. Compared to the previous SIR 2011 guidelines (11), an update was made on

Table VII - Final set of Recommendations on treatment strategy in RA (Safety).

\begin{tabular}{|c|c|c|c|}
\hline No. & The final set of "Safety" Recommendations & $\begin{array}{l}\text { Category } \\
\text { of Evidence }\end{array}$ & $\begin{array}{c}\text { Grade of } \\
\text { Recommendation }\end{array}$ \\
\hline 1 & $\begin{array}{l}\text { TUBERCULOSIS } \\
\text { Screening for TB is recommended prior to starting bDMARD or tsDMARD therapy. Initial TST } \\
\text { or IGRA is recommended. IGRA is preferred if patient has a history of BCG vaccination.* } \\
\text { a) Patients with a positive initial or repeat TST or IGRA should have a chest radiograph and, } \\
\text { if positive for past TB exposure or active TB, a subsequent sputum examination to check } \\
\text { for the presence of active TB. } \\
\text { b) Patients with a negative screening TST or IGRA may not need further workup in the absence } \\
\text { of risk factors and/or clinical suspicion for TB.. } \\
\text { c) If the RA patient has active or latent TB based on the test results the panel recommends } \\
\text { appropriate anti-tubercular treatment and consideration for referral to a specialist. }{ }^{\dagger} \\
\text { d) Treatment with tsDMARDs or bDMARDs can be initiated or resumed after } 1 \text { month of latent } \\
\text { TB treatment with anti-tubercular medications and after completion of the treatment } \\
\text { of active TB, if applicable according to reference specialist (pulmonologist or infectious } \\
\text { disease specialist).* } \\
\text { e) Annual testing is recommended in RA patients who live, travel or work in situations } \\
\text { where TB exposure is likely while they continue treatment with biologics. }{ }^{*}\end{array}$ & $2^{*}$ & $\begin{array}{l}\mathrm{C}^{*} \\
\mathrm{~B}^{\dagger}\end{array}$ \\
\hline 2 & $\begin{array}{l}\text { HBV INFECTION } \\
\text { a) All RA patients should be screened for HBsAg, antiHBsAb e antiHBcAb especially } \\
\text { before starting a bDMARD or a tsDMARD.* } \\
\text { b) AntiHBcAb positive, HBsAg negative patients should undergo further evaluations, including } \\
\text { HBV, DNA and liver function tests before starting immunosuppressive therapy. RA treatment } \\
\text { should be the same as that for unexposed patients, as long as the patient's viral load } \\
\text { is monitored regularly, every } 6-12 \text { months. } \\
\text { c) HBsAg positive patients should undergo further evaluation, including quantitative HBsAg, } \\
\text { HBeAg, antiHBe, HBV DNA and anti HDV IgG and liver function tests, before starting } \\
\text { immunosuppressive therapy. } \\
\text { d) Active HBV carriers should be treated with entecavir or tenofovir in accordance } \\
\text { with the international guidelines before starting immunosuppressive therapy. } \\
\text { e) Acute HB occurring in patients with RA, such as asymptomatic infections occurring } \\
\text { in patients previously negative for HBV serology, should receive antiviral treatment } \\
\text { according to international guidelines. }{ }^{\dagger} \\
\text { f) In inactive HBV carriers, prophylaxis should be started } 4 \text { weeks before the } \\
\text { immunosuppressive therapy and continued for } 12 \text { months after its discontinuation } \\
\text { (24 months in the case of rituximab-treated patients).* } \\
\text { g) Patients stopping prophylaxis should be closely monitored. }{ }^{\ddagger}\end{array}$ & $\begin{array}{l}2^{\star} \\
1^{\dagger} \\
5^{\S} \\
5^{\ddagger}\end{array}$ & $\begin{array}{l}\mathrm{B}^{\star} \\
\mathrm{A}^{\dagger} \\
\mathrm{B}^{\S} \\
\mathrm{C}^{\ddagger}\end{array}$ \\
\hline
\end{tabular}




\begin{tabular}{|c|c|c|c|}
\hline No. & The final set of "Safety" Recommendations & $\begin{array}{l}\text { Category } \\
\text { of Evidence }\end{array}$ & $\begin{array}{c}\text { Grade of } \\
\text { Recommendation }\end{array}$ \\
\hline 3 & $\begin{array}{l}\text { HCV INFECTION } \\
\text { a) All RA patients should be screened for HCV infections, especially before starting } \\
\text { a bDMARDs or tsDMARDs. } \\
\text { b) RA patients with HCV infection should undergo gastroenterological / infectious evaluation } \\
\text { for any anti-viral eradicative therapy and should not be treated differently from patients } \\
\text { with AR without HCV infection. }{ }^{\dagger}\end{array}$ & $\begin{array}{l}2^{\star} \\
5^{\dagger}\end{array}$ & $\begin{array}{l}\mathrm{B}^{\star} \\
\mathrm{D}^{\dagger}\end{array}$ \\
\hline 4 & $\begin{array}{l}\text { CARDIOVASCULAR DISEASE } \\
\text { a) CVD risk assessment is recommended for all patients with RA at least once every } 5 \text { years } \\
\text { and should be reconsidered following major changes in antirheumatic therapy. CVD risk } \\
\text { estimation for patients with RA should be performed according to national guidelines and the } \\
\text { SCORE CVD risk prediction model should be used if no national guideline is available..* } \\
\text { b) CVD risk prediction models should be adapted for patients with RA by a } 1.5 \text { multiplication } \\
\text { factor, if this is not already included in the model. } \\
\text { c) Screening for asymptomatic atherosclerotic plaques by use of carotid ultrasound may } \\
\text { be considered as part of the CVD risk evaluation in patients with RA. }{ }^{*} \\
\text { d) Lifestyle recommendations should emphasize the benefits of a healthy diet, regular exercise } \\
\text { and giving up smoking for all patients. } \\
\text { e) In CVD risk management, antihypertensives and statins may be used as in the general } \\
\text { population.* } \\
\text { f) Prescription of NSAIDs in RA should be given with caution, especially for patients } \\
\text { with documented CVD or in the presence of CVD risk factors. }{ }^{*}\end{array}$ & $\begin{array}{l}3^{\dagger} \\
2^{\S}\end{array}$ & $\begin{array}{l}D^{*} \\
C^{\dagger} \\
A^{\S}\end{array}$ \\
\hline 4 & $\begin{array}{l}\text { g) In case of Congestive Heart Failure: use combination of csDMARDs or non TNF-i } \\
\text { or tsDMARDs rather than TNF-i.† } \\
\text { h) Congestive Heart Failure worsening on current TNF-i therapy: use combination } \\
\text { of csDMARDs or non-TNF-i or tsDMARDs rather than TNF-i.* } \\
\text { i) A TNF-i should only be used if there are no other reasonable options, and then, } \\
\text { perhaps, only in compensated heart failure. }{ }^{*}\end{array}$ & $\begin{array}{l}4^{*} \\
3^{\dagger} \\
2^{\S}\end{array}$ & $\begin{array}{l}D^{*} \\
C^{\dagger} \\
A^{\S}\end{array}$ \\
\hline 5 & $\begin{array}{l}\text { MALIGNANCY } \\
\text { If the disease is moderately or highly active in the setting of a low-grade melanoma } \\
\text { or non-melanoma skin cancer that had been previously treated, biologics would be an } \\
\text { acceptable option with close skin surveillance in conjunction with a dermatologist.* } \\
\text { a) In general } \\
\text { - use csDMARDs rather than tsDMARDs or bDMARDs. } \\
\text { b) Previously treated lymphoproliferative disorders: } \\
\text { - use Rituximab rather than TNF-i.t. } \\
\text { - use combination of csDMARDs or Abatacept or Tocilizumab rather than TNF-i.* } \\
\text { c) Previously treated solid organ malignancy } \\
\text { - same recommendations as in patients without this condition (in the absence of active } \\
\text { malignancy, according to the reference specialist).. }\end{array}$ & $5^{\dagger}$ & $\begin{array}{l}D^{*} \\
C^{\dagger}\end{array}$ \\
\hline 6 & $\begin{array}{l}\text { VACCINATION } \\
\text { a) Ideally administration of all vaccines, if indicated, should be undertaken at least } 4 \text { weeks } \\
\text { before starting a tsDMARD or bDMARD. } \\
\text { b) Concurrent administration of live, attenuated vaccines is an absolute contraindication } \\
\text { for patients being treated with tsDMARDs or bDMARDs.* } \\
\text { Killed vaccines (Pneumococcal, Influenza^, Hepatitis B) are recommended, before initiating } \\
\text { or during therapy with csDMARDs, tsDMARDs, bDMARDs, in RA patients. } \\
\text { (^every year according to epidemiology). } \\
\text { c) Recombinant Vaccine (Human Papilloma) is recommended before initiating or during } \\
\text { therapy with csDMARDs, tsDMARDs, bDMARDs in RA patients (according to National } \\
\text { Recommendations). }{ }^{*}\end{array}$ & $4^{*}$ & $\begin{array}{l}D^{*} \\
A^{\dagger}\end{array}$ \\
\hline
\end{tabular}

RA, Rheumatoid Arthritis; TB, Tuberculosis, TST, Tuberculosis Skin Test; IGRA, Interferon Gamma Release Assay; BCG, Bacillus Calmette-Guerine; HBV, Hepatitis B Virus, HBsAb, Hepatitis B Surface antibodies; HBsAg, Hepatitis B Surface Antigen; HBcAb, Hepatitis B core anti-bodies; HBeAb, Hepatitis B envelope anti-bodies, HBeAg, Hepatitis B envelope antigen; HDV, Hepatitis D Virus; AST, Aspartate Aminotransferase; ALT, Alanine Aminotransferase; GGT, Gamma Glutamyl Transferase; INR, International Normalized Ratio; CVD, Cardiovascular Disease; NSAID, Non-Steroidal Anti Inflammatory Drug; MTX, Methotrexate; LFN, Leflunomide; SSZ, sulfasalazine; csDMARD, conventional synthetic disease-modifying antirheumatic drug; bDMARD, biologic disease-modifying antirheumatic drug; tsDMARD, target synthetic disease-modifying antirheumatic drug; TNF-i, Tumor Necrosis Factor inhibitor; JAK-i, janus kinase inhibitor. The symbols $\left({ }^{*},{ }^{\dagger}, \S, \ddagger\right)$ relate to the corresponding symbols in the recommendations, showing in the respective grade. 
the drugs available, and tsDMARDs were included. The role of therapy with methotrexate is confirmed, which remains the first drug of choice in the treatment of RA. The association of a csDMARD (monotherapy) with glucocorticoids is more strongly suggested than before in terms of efficacy and safety, considering increasing evidence that this combination is not surpassed by csDMARD combinations (with glucocorticoids or with bDMARDs plus MTX) $(151,152)$. Moreover, the importance of prognostic factors as drivers in the therapeutic strategy is reaffirmed. Furthermore, the strategy to be adopted in case of failure of the bDMARDs has been redefined. Considering a continuously increasing spectrum of therapeutic options and new information on existing agents and therapeutic strategies, this update covers new treatment aspects and is

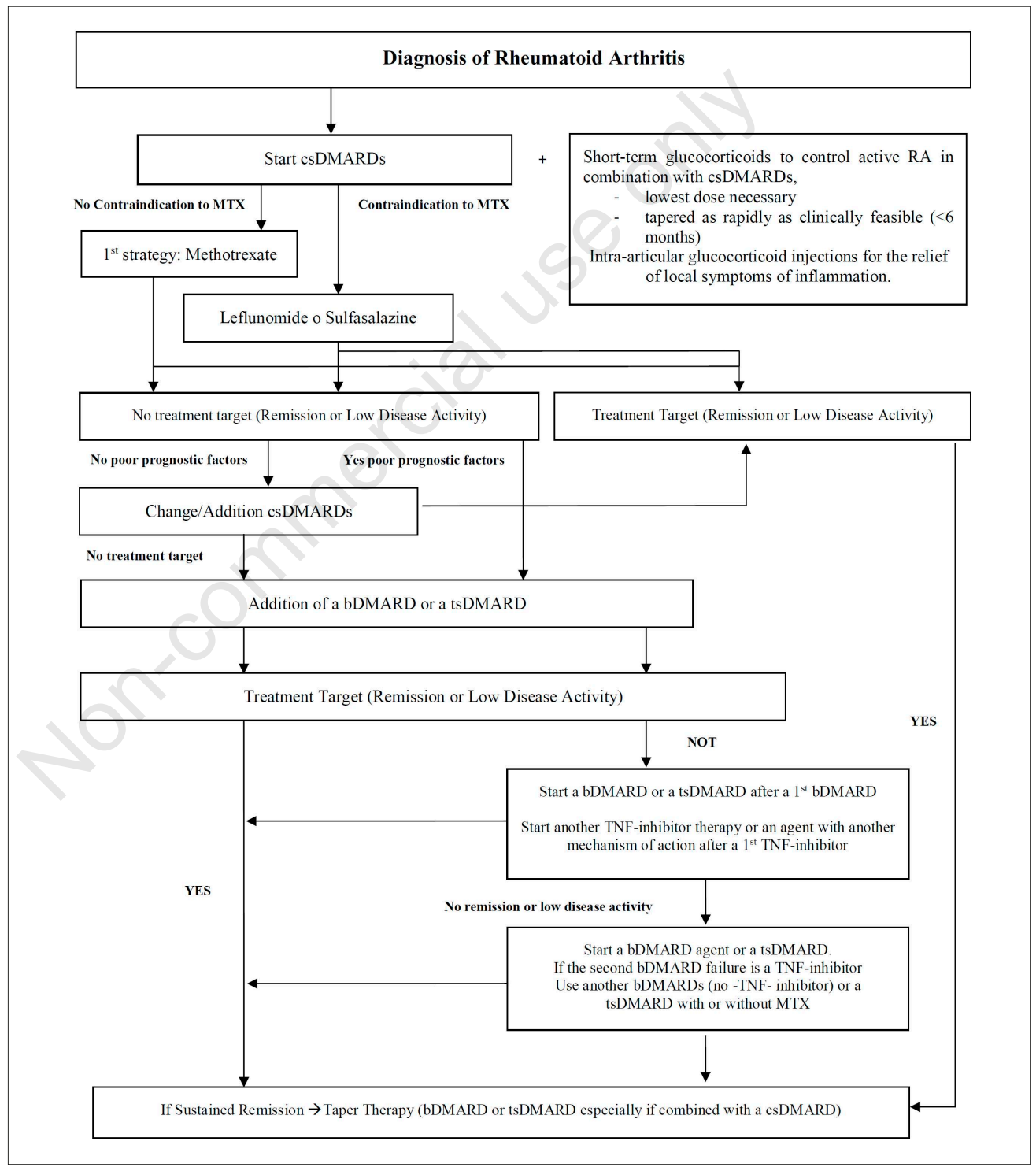

Figure 2 - Algorithm of treatment in RA.

RA, rheumatoid arthritis; MTX, methotrexate; csDMARD, conventional synthetic diseasemodifying antirheumatic drug; bDMARD, biologic disease-modifying antirheumatic drug; tsDMARD, target synthetic disease-modifying antirheumatic drug; TNF-inhibitor, tumor necrosis factor inhibitor; JAK-i, janus kinase inhibitor. 
built on strong and consistent evidence. The preferred instruments to be used when following patients were defined in accordance with EULAR and comprised composite measures, such as the CDAI, DAS28 and SDAI as well as the ACR/EULAR remission definitions $(153,154)$. We confirm the concept of short-term glucocorticoids, instead of low dose according to the EULAR recommendations, since various modes of application at different doses have proved to be efficacious. Moreover, the most important factors for reducing the risk of adverse events, such as CV events, infections, diabetes or hypertension (155-157), acknowledged the rapid tapering to discontinuation and a low cumulative dose of glucocorticoids $(151,158)$. In patients who cannot use csDMARDs as comedication, the EULAR Task Force indicated treatment inhibiting the IL- 6 pathway and tsDMARDs as preferential since they may have some advantages compared with other bDMARDs. However, the studies on tocilizumab considered were only those of intravenous administration, while the drug is now widely used subcutaneously (159). For baricitinib only trial data are available (43-45). The rheumatologist is not only called into question for the therapeutic strategy based on the activity of the disease but is also responsible for the evaluation of the consequences and implications in the safety of the treatment. However, important data are still unknown. The question regarding how much time must elapse before considering a therapy non-optimal (not in remission or in LDA) and which parameters to use, could not be answered. Neither could that concerning the effect of different modes of action of antirheumatic drugs on $C V D$ risk, especially JAK-i. The clinical trials did not address the efficacy of a TNF-i after other mechanisms of action (no-antiTNF-i or JAK-i) or the efficacy of IL-6R as sarilumab after tocilizumab. Furthermore, there appears to be an increase in cases of Herpes Zoster and thrombosis during therapy with tsDMARDs which should be carefully monitored (160, 161-167). Some recommendations were strong despite low quality evidence and the panel provided justification for these recommendations. This indicates that more significant evidence is needed to derive strong recommendations in the future.

\section{Plans of update}

These recommendations were endorsed by SIR as guidelines only and they do not substitute the individual clinicians' judgment since they may not apply to all patients and all clinical situations. The SIR plans to review and update these recommendations in the future to determine if they remain current and to capture future treatments or advances in the management of RA.

Acknowledgements: the Authors acknowledge all the external reviewers (in alphabetical order of those who gave consent for publication): S. Bugatti, M.S. Chimenti, S. Guiducci, F. Iannone, C. Lomater, V. Mascheroni, B. Raffeiner R. Scrivo, M. Sebastiani, S. Tonolo. We are grateful to Solazzo T. as part of the SIR secretariat for administrative support.

Contributions: all authors were involved in drafting the article or revising it critically for important intellectual content, and all authors approved the final version for publication. Concept and design: C.A.S., S.P., A.B., M.M., I.P., A.A., N.U. Systematic review search and CPGs rating: S.P., A.B. Analysis and discussion of the recommendations: S.P., A.B., G.D.S., F.C., R.C., M.M., I.P., N.U., A.A., C.A.S..

Funding: these recommendations matched no specific funding from any bodies in the public, commercial sectors or any nonprofit organization. Non-economic support, such as meeting rooms and secretariat services, was provided by SIR to carry out the work described in this manuscript.

Disclosure statements: S.P. reports a grant from SIR and others related to advisory boards from AbbVie, Celgene, Janssen, Biogen, Bristol-Myers Squibb, Sanofi, and others related to scientific advice from Baldacci, and Chiesi outside the submitted work; A.B. reports honoraria due to advisory board from GlaxoSmithKline outside the submitted work; F.C reports speaker 
fees from Bristol-Myers Squibb, AbbVie, Pfizer, Lilly and Merck Sharp \& Dohme; R. C. reports speaker fees related to advisory boards from Abbvie, Bristol Myers Squibb, Celgene, Gilead, Janssen, Lilly, Merck Sharp \& Dohme, Novartis, Pfizer, Roche and Sanofi; M.M. reports a grant from SIR, honoraria due to advisory boards from Celgene and Sanofi and others from Lilly, Alfa
Wassermann, Novartis, Merck Sharp \& Dohme outside the submitted work; I.P. reports a grant from SIR and honoraria due to advisory board from AbbVie; A.A. reports a grant from SIR; N.U. reports a grant from SIR and honoraria for consultations from Mundipharma Pharmaceuticals outside the submitted work. All other authors have declared no conflicts of interest.

\section{APPENDIX 1}

\section{KEYWORDS FOR THE SYSTEMATIC LITERATURE SEARCH}

\section{Medline via Pubmed}

("arthritis, rheumatoid" [MeSH Terms] OR ("arthritis" [All Fields] AND "rheumatoid" [All Fields]) OR "rheumatoid arthritis" [All Fields] OR ("rheumatoid" [All Fields] AND "arthritis" [All Fields])) AND ("Practice Guideline" [Publication Type] OR "Practice Guidelines As Topic" [MeSH Terms] OR (("Practice (Birm)" [Journal] OR "practice" [All Fields]) AND "guidelines as topic" [MeSH Terms]) OR Practice Guideline [Text Word] OR Practice Guidelines [Text Word] OR "Guideline" [Publication Type] OR "Guidelines As Topic" [MeSH Terms] OR "guidelines as topic" [MeSH Terms] OR Guideline [Text Word] OR Guidelines [Text Word] OR "Consensus Development Conference" [Publication Type] OR ("consensus development conference" [Publication Type] OR "consensus development conferences as topic" [MeSH Terms] OR "consensus development conference" [All Fields]) AND Topic [All Fields]) OR "consensus" [MeSH Terms] OR Consensus [Text Word] OR Recommendation [Text Word] OR Recommendations [Text Word] OR "practice guidelines as topic" [MeSH Terms] OR Best Practice [Text Word] OR "practice guidelines as topic" [MeSH Terms] OR Best Practices [Text Word]) AND (“2012/07/13” [PDAT] "2017/07/11” [PDAT]).

\section{Embase}

'rheumatoid arthritis'/de AND ('practice guideline'/exp OR 'practice guideline' OR 'practice guidelines/exp' OR 'practice guidelines' OR 'clinical practice guideline'/exp OR 'clinical practice guideline' OR 'clinical practice guidelines'/exp OR 'clinical practice guidelines' OR 'clinical practice guidelines as topic'/exp OR 'clinical practice guidelines as topic' OR 'guideline'/exp OR 'guideline' OR 'guidelines'/exp OR 'guidelines' OR 'guidelines as topic'/exp OR 'guidelines as topic' OR 'consensus development'/exp OR 'consensus development' OR 'consensus development conference'/exp OR 'consensus development conference' OR 'consensus development conferences'/exp OR 'consensus development conferences' OR ‘consensus development conferences as topic'/exp OR 'consensus development conferences as topic' OR 'consensus'/exp OR 'consensus' OR 'recom- mendation' OR 'recommendations') AND (2013:py OR 2014:py OR 2015:py OR 2016:py OR 2017:py) AND [embase]/lim NOT [medline]/lim.

\section{Grey Literature}

English Grey Literature

Grey Literature Report (http://www.greylit.org) http://www.greylit.org/content/safety-vaccines-usedroutine-immunization-united-states

Maglione MA, Gidengil C, Das L, et al. Safety of Vaccines Used for Routine Immunization in the United States. Rockville (MD): Agency for Healthcare Research and Quality (US); 2014 Jul. (Evidence Reports/ Technology Assessments, No. 215.) Addendum.

Agency for Healthcare Research and Quality (https:// www.guideline.gov/search? $\mathrm{q}=\% 22$ rheumatoid+arthri tis $\% 22 \& f$ dateRangeFrom $=2013 \& f$ dateRangeTo $=2$ 016\&page $=1 \&$ pageSize $=50$ ).

National Guideline Clearinghouse (NGC). Guideline summary: adalimumab, etanercept, infliximab, certolizumab pegol, golimumab, tocilizumab and abatacept for rheumatoid arthritis not previously treated with DMARDs or after conventional DMARDs only have failed. In: National Guideline Clearinghouse (NGC) [Web site]. Rockville (MD): Agency for Healthcare Research and Quality (AHRQ); 2016 Jan 26. [cited 2017 Jul 02]. Available: https://www.guideline.gov. Dynamed Plus http://www.dynamed.com/topics/dmp $\sim$ AN T115261/Rheumatoid-arthritis-RA?filter =all National Library of Medicine, or "Vancouver style" (International Committee of Medical Journal Editors): DynaMed Plus [Internet]. Ipswich (MA): EBSCO Information Services. 1995 -. Record No. 115261, Rheumatoid arthritis (RA); [updated 2017 Jun 05, cited place cited date here]; [about 60 screens]. Available from http://www.dynamed.com/login.aspx?direc $\mathrm{t}=$ true \& site $=$ DynaMed\&id $=115261$.

Italian Grey Literature

Google: http://www.clinexprheumatol.org/a.asp? IDArchivio=123 Consiglio Nazionale delle ricerche (CNR) (http://polarcnr.area.ge.cnr.it/cataloghi/bice/ index.php?type=Grigia): nessuno 


\section{APPENDIX 2}

\section{LEVEL OF AGREEMENT (SCORE 1-10) FOR EACH REVISED RECOMMENDATION RATED BY THE MULTIDISCIPLINARY EXTERNAL COMMISSION (N=10). A MINIMUM SCORE $\geq 7$ WAS USED A PRIORI TO CONSIDER EACH RECOMMENDATION ACCEPTABLE FOR CLINICAL PRACTICE PURPOSES}

\begin{tabular}{|c|c|}
\hline $\mathbf{N}^{\circ}$ Item management & Level of agreement, median (range) \\
\hline 1 & $10(8-10)$ \\
\hline 2 & $10(8-10)$ \\
\hline 3 & $9,5(6-10)$ \\
\hline 4 & $10(6-10)$ \\
\hline 5 & $8,5(4-10)$ \\
\hline 6 & $8,5(7-10)$ \\
\hline 7 & $9(5-10)$ \\
\hline 8 & $8,5(5-10)$ \\
\hline $\mathbf{N}^{\circ}$ Item management & Level of agreement, median (range) \\
\hline 1 & $8(3-10)$ \\
\hline 2 & $8(3-10)$ \\
\hline 3 & $8(3-10)$ \\
\hline 4 & $8,5(6-10)$ \\
\hline 5 & $8(4-10)$ \\
\hline 6 & $9(5-10)$ \\
\hline
\end{tabular}

\section{APPENDIX 3}

GLOSSARY AND DEFINITIONS (Adapted from ref 16)

\begin{tabular}{|l|l|}
\hline Term & Definition \\
\hline Low-dose glucocorticoid & $\leq 7.5 \mathrm{mg} /$ day (prednisone equivalent). \\
\hline Tapering & $\begin{array}{l}\text { Usually reduction of drug dose or increase of application interval (spacing). } \\
\text { May include discontinuation (tapering to 0), but then only after slow reduction. }\end{array}$ \\
\hline Discontinuation & Stopping of a particular drug. \\
\hline Cycling (Switch) Strategy & Change drug with the same mode of action in RA patients failing TNF-inhibitors. \\
\hline Swapping (Swap) Strategy & Change drug with another mode of action in RA patients failing TNF-inhibitors. \\
\hline Synthetic DMARDs & $\begin{array}{l}\text { Conventional synthetic DMARDs (csDMARDs): methotrexate, leflunomide, } \\
\text { sulfasalazine, hydroxychloroquine. }\end{array}$ \\
\hline $\begin{array}{l}\text { Target synthetic DMARDs } \\
\text { (tsDMARDs/JAK-i): baricitinib, } \\
\text { tofacitinib. }\end{array}$ & $\begin{array}{l}\text { Biologici Originatori/Biosimilari (bDMARDs): abatacept, adalimumab, } \\
\text { certolizumab pegol, etanercept, golimumab, infliximab, rituximab, } \\
\text { sarilumab, tocilizumab. }\end{array}$ \\
\hline Biological DMARDs & $\begin{array}{l}\text { Biological Originator/Biosimilar (bDMARDs): abatacept, adalimumab, } \\
\text { certolizumab pegol, etanercept, golimumab, infliximab, rituximab, sarilumab, } \\
\text { tocilizumab. }\end{array}$ \\
\hline
\end{tabular}

$\mathrm{RA}$, rheumatoid arthritis; csDMARD, conventional synthetic disease-modifying antirheumatic drug; bDMARD, biologic disease-modifying antirheumatic drug; tsDMARD, target synthetic disease-modifying antirheumatic drug; TNF-inhibitor, tumor necrosis factor inhibitor; JAK-i, janus kinase inhibitor. 


\section{BIBLIOGRAFIA}

1. Helmick CG, Felson DT, Lawrence RC, et al. Estimates of the prevalence of arthritis and other rheumatic conditions in the United States: part I. Arthritis Rheum. 2008; 58: 15-25.

2. McInnes IB, Schett G. The pathogenesis of rheumatoid arthritis. N Engl J Med. 2011; 365: 2205-19.

3. Turesson C, Jacobsson L, Bergstrom U. Extraarticularrheumatoid arthritis: prevalence and mortality. Rheumatology (Oxford). 1999; 38: 668-74.

4. Moreland L. Unmet needs in rheumatoid arthritis. Arthritis Res Ther. 2005; 7: S2-8.

5. Pincus T, Callahan LF, SaleWG, et al. Severe functional declines, work disability, and increased mortality in seventy-five rheumatoid arthritis patients studied over nine years. Arthritis Rheum. 1984; 27: 864-72.

6. Salaffi F, Sarzi-Puttini P, Girolimetti R, et al. Health-related quality of life in fibromyalgia patients: a comparison with rheumatoid arthritis patients mand the general population using the SF-36 health survey. Clin Exp Rheumatol. 2009; 27: S67-74.

7. Emery P, Salmon M. Early rheumatoid arthritis: time to aim for remission? Ann Rheum Dis. 1995; 54: 944-7.

8. Smolen JS, van der Heijde D, Machold KP, et al. Proposal for a new nomenclature of disease-modifying antirheumatic drugs. Ann Rheum Dis. 2014; 73: 3-5.

9. Visser K, van der Heijde D. Optimal dosage and route of administration of methotrexate in rheumatoid arthritis: a systematic review of the literature. Ann Rheum Dis. 2009; 68: 1094-9.

10. Smolen JS, Aletaha D, McInnes IB. Rheumatoid arthritis. Lancet. 2016; 388: 2023-38.

11. Caporali R, Conti F, Alivernini S, et al. Italian Society for Rheumatology. Recommendations for the use of biologic therapy in rheumatoid arthritis: update from the Italian Society for Rheumatology I. Efficacy. Clin Exp Rheumatol. 2011; 29: S7-14.

12. Favalli EG, Caporali R, Sinigaglia L, et al. Italian Society for Rheumatology. Recommendations for the use of biologic therapy in rheumatoid arthritis: update from the Italian Society for Rheumatology II. Safety. Clin Exp Rheumatol. 2011; 29: S15-27.

13. Fervers B, Burgers JS, Haugh MC, et al. Adaptation of clinical guidelines: literature review and proposition for a framework and procedure. Int J Qual Health Care. 2006; 18: 167-76.

14. Fervers B, Burgers JS, Voellinger R, et al. Guideline adaptation: an approach to enhance efficiency in guideline development and improve utilisation. BMJ Qual Saf. 2011; 20: 228-36.
15. Smolen JS, Landewè R, Breedveld FC, et al. EULAR recommendations for the management of rheumatoid arthritis with synthetic and biological disease-modifying antirheumatic drugs. Ann Rheum Dis. 2010; 69: 964-75.

16. Smolen JS, Landewé R, Bijlsma J, et al. EULAR recommendations for the management of rheumatoid arthritis with synthetic and biological disease-modifying antirheumatic drugs: 2016 update. Ann Rheum Dis. 2017; 76: $960-77$.

17. Singh JA, Saag KG, Bridges SL Jr, et al. 2015 American College of Rheumatology Guideline for the Treatment of Rheumatoid Arthritis. Arthrit Rheum. 2016; 68: 1-26.

18. Brouwers MC, Kho ME, Browman GP, et al. AGREE II: advancing guideline development, reporting and evaluation in health care. CMAJ. 2010; 182: E839-42.

19. Oxford Centre for Evidence-based Medicine. Levels of Evidence; March 2009. Available from: http://www.cebm.net/oxford-centreevidence-based-medicine-levels-evidencemarch-2009/

20. Brouwers MC, Kerkvliet K, Spithoff K. The AGREE Reporting Checklist: a tool to improve reporting of clinical practice guidelines. BMJ. 2016; 352: i1152.

21. Vastesaeger N, Xu S, Aletha D, Smolen JS. 2016 A pilot risk model for the prediction of rapid radiographic progression in rheumatoid arthritis. Rheumatology (Oxford). 2009; 48: 1114-21.

22. Combe B, Landewe R, Daien CI, et al. 2016 update of the EULAR recommendations for the management of early arthritis. Ann Rheum Dis. 2017; 76: 948-59.

23. Agca R, Heslinga SC, Rollefstad S, et al. EULAR recommendations for cardiovascular disease risk management in patients with rheumatoid arthritis and other forms of inflammatory joint disorders: 2015/2016 update. Ann Rheum Dis. 2017; 76: 17-28.

24. Singh JA, Furst DE, Bharat A, et al. 2012 update of the 2008 American College of Rheumatology recommendations for the use of disease-modifying antirheumatic drugs and biologic agents in the treatment of rheumatoid arthritis. Arthritis Care Res (Hoboken). 2012; 64: 625-39.

25. Sebastiani M, Atzeni F, Milazzo L, et al. Italian consensus Guidelines for the management of hepatitis B virus infections in patients with rheumatoid arthritis. Joint Bone Spine. 2017; 84: 525-30.

26. Moura CS, Abrahamowicz M, Beauchamp ME, et al. Early medication use in new-onset rheumatoid arhtirtis may delay joint replacement: results of a large population-based study. Arthritis Res Ther. 2015; 17: 197.

27. Choi HK, Hernán MA, Seeger JD, et al. Me- 
thotrexate and mortality in patients with rheumatoid arthritis: a prospective study. Lancet. 2002; 359: 1173-7.

28. Wasko MC, Dasgupta A, Hubert H, Fries JF, Ward MM. Propensity-adjusted association of methotrexate with overall survival in rheumatoid arthritis. Arthritis Rheum. 2013; 65: 334-42.

29. Daien CI, Hua C, Combe B, Landewe R. Non-pharmacological and pharmacological interventions in patients with early arthritis: a systematic literature review informing the 2016 update of EULAR recommendations for the management of early arthritis. RMD Open. 2017; 3: e000404.

30. Gaujoux-Viala C, Smolen JS, Landewé R, et al. Current evidence for the management of rheumatoid arthritis with synthetic diseasemodifying antirheumatic drugs: a systematic literature review informing the EULAR recommendations for the management of rheumatoid arthritis. Ann Rheum Dis. 2010; 69: 1004-9.

31. Emery P, Breedveld FC, Lemmel EM, et al. A comparison of the efficacy and safety of leflunomide and methotrexate for the treatment of rheumatoid arthritis. Rheumatol (Oxford). 2000; 39: 655-65.

32. Strangfeld A, Hierse F, Kekow J, et al. Comparative effectiveness of tumour necrosis factor alpha inhibitors in combination with either methotrexate or leflunomide. Ann Rheum Dis. 2009; 68: 1856-62.

33. De Stefano R, Frati E, Nargi F, et al. Comparison of combination therapies in the treatment of rheumatoid arthritis: leflunomide-antiTNF-alpha versus methotrexate-anti-TNFalpha. Clin Rheumatol. 2010; 29: 517-24.

34. Burmester GR, Mariette X, Montecucco C, et al. Adalimumab alone and in combination with disease-modifying antirheumatic drugs for the treatment of rheumatoid arthritis in clinical practice: the Research in Active Rheumatoid Arthritis (ReAct) trial. Ann Rheum Dis. 2007; 66: 732-9.

35. Genovese MC, McKay JD, Nasonov EL, et al. Interleukin-6 receptor inhibition with tocilizumab reduces disease activity in rheumatoid arthritis with inadequate response to diseasemodifying antirheumatic drugs: the tocilizumab in combination with traditional diseasemodifying antirheumatic drug therapy study. Arthritis Rheum. 2008; 58: 2968-80.

36. Van der Heijde DM, van Riel PL, Nuver-Zwart IH. Sulphasalazine versus hydroxychloroquine in rheumatoid arthritis: 3-year follow-up. Lancet. 1990; 335: 539.

37. Van Vollenhoven RF, Geborek P, Forslind K, et al. Conventional combination treatment versus biological treatment in methotrexaterefractory early rheumatoid arthritis: 2 year follow-up of the randomised, non-blinded, parallel-group Swefot trial. Lancet. 2012; 379: 1712-20.
38. Kume K, Amano K, Yamada S, et al. Tocilizumab monotherapy reduces arterial stiffness as effectively as etanercept or adalimumab monotherapy in rheumatoid arthritis: an open-label randomized controlled trial. J Rheumatol. 2011; 38: 2169-71.

39. Weinblatt ME, Schiff M, Valente R, et al. Head-to-head comparison of subcutaneous abatacept versus adalimumab for rheumatoid arthritis: findings of a phase IIIb, multinational, prospective, randomized study. Arthritis Rheum. 2013; 65: 28-38.

40. Yoo DH, Prodanovic N, Jaworski J, et al. Efficacy and safety of CT-P13 (biosimilar infliximab) in patients with rheumatoid arthritis: comparison between switching from reference infliximab to CT-P13 and continuing CTP13 in the PLANETRA extension study. Ann Rheum Dis. 2017; 76: 355-63.

41. Choe JY, Prodanovic N, Niebrzydowski J, et al. A randomised, double-blind, phase III study comparing SB2, an infliximab biosimilar, to the infliximab reference product Remicade in patients with moderate to severe rheumatoid arthritis despite methotrexate therapy. Ann Rheum Dis. 2017; 76: 58-64.

42. Emery P, Vencovsky J, Sylwestrzak A, et al. A phase III randomised, double-blind, parallelgroup study comparing SB4 with etanercept reference product in patients with active rheumatoid arthritis despite methotrexate therapy. Ann Rheum Dis. 2017; 76: 51-7.

43. Taylor PC, Keystone EC, van der Heijde D, et al. Baricitinib versus placebo or adalimumab in patients with active rheumatoid arthritis (RA) and an inadequate response to background methotrexate therapy: results of a phase 3 study. Arthritis Rheum. 2015; 67: L2.

44. Burmester GR, Rigby WF, van Vollenhoven $\mathrm{RF}$, et al. Tocilizumab in early progressive rheumatoid arthritis: FUNCTION, a randomised controlled trial. Ann Rheum Dis. 2016; 75 : 1081-91.

45. Kaneko Y, Atsumi T, Tanaka Y, et al. Comparison of adding tocilizumab to methotrexate with switching to tocilizumab in patients with rheumatoid arthritis with inadequate response to methotrexate: 52-week results from a prospective, randomised, controlled study (SURPRISE study). Ann Rheum Dis. 2016; 75 : 1917-23.

46. Dougados M, Kissel K, Conaghan PG, et al. Clinical, radiographic and immunogenic effects after 1 year of tocilizumab-based treatment strategies in rheumatoid arthritis: the ACT-RAY study. Ann Rheum Dis. 2014; 73 : 803-9.

47. Torrente-Segarra V, Acosta Pereira A, Morla $\mathrm{R}$, et al. VARIAR study: assessment of shortterm efficacy and safety of rituximab compared to an tumor necrosis factor alpha antago- 
nists as second-line drug therapy in patients with rheumatoid arthritis refractory to a first tumor necrosis factor alpha antagonist. Reumatol Clin. 2016; 12: 319-22.

48. Manders SH, Kievit W, Adang E, et al. Costeffectiveness of abatacept, rituximab, and TNFi treatment after previous failure with TNFi treatment in rheumatoid arthritis: a pragmatic multi-centre randomised trial. Arthritis Res Ther. 2015; 17: 134.

49. Schoels M, Aletaha D, Smolen JS, et al. Comparative effectiveness and safety of biological treatment options after tumour necrosis factor

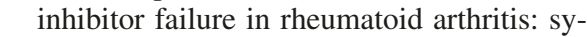
stematic review and indirect pairwise metaanalysis. Ann Rheum Dis. 2012; 71: 1303-8.

50. Johnston SS, Turpcu A, Shi N, et al. Risk of infections in rheumatoid arthritis patients switching from anti-TNF agents to rituximab, abatacept, or another anti-TNF agent: a retrospective administrative claims analysis. Semin Arthritis Rheum. 2013; 43: 39-47.

51. Gomez-Reino JJ, Maneiro JR, Ruiz J, et al. Comparative effectiveness of switching to alternative tumour necrosis factor (TNF) antagonists versus switching to rituximab in patients with rheumatoid arthritis who failed previous TNF antagonists: the MIRAR Study. Ann Rheum Dis. 2012; 71: 1861-4.

52. Finckh A, Ciurea A, Brulhart L, et al. Which subgroup of patients with rheumatoid arthritis benefits from switching to rituximab versus alternative anti-tumour necrosis factor (TNF) agents after previous failure of an anti-TNF agent? Ann Rheum Dis. 2010; 69: 387-93.

53. Fleischmann R, Cutolo M, Genovese MC, et al. Phase IIb dose-ranging study of the oral JAK inhibitor tofacitinib (CP-690,550) or adalimumab monotherapy versus placebo in patients with active rheumatoid arthritis with an inadequate response to disease-modifying antirheumatic drugs. Arthritis Rheum. 2012; 64: 617-29.

54. Van Vollenhoven RF, Fleischmann R, Cohen $\mathrm{S}$, et al. Tofacitinib or adalimumab versus placebo in rheumatoid arthritis. N Engl J Med. 2012; 367: 508-19.

55. Center for Diseases Control. Targeted tuberculin testing and treatment of latent tuberculosis infection. MMWR. 2000; 49: RR-6.

56. Singh JA, Noorbaloochi S, Singh G. Golimumab for rheumatoid arthritis. Cochrane Database Syst Rev. 2010; (1): CD008341.

57. Singh JA, Beg S, Lopez-Olivo MA. Tocilizumab for rheumatoid arthritis. Cochrane Database Syst Rev. 2010; 7: CD008331.

58. Cantini Harris J, Keane J. How tumour necrosis factor blockers interfer with tuberculosis immunity. Clin Exp Immunol. 2010; 161: 1-9.

59. Cantini F, Niccoli L, Goletti D. Tuberculosis risk in patients treated with non-anti-tumor necrosis factor- $\alpha$ (TNF- $\alpha)$ targeted biologics and recently licensed TNF- $\alpha$ inhibitors: data from clinical trials and national registries. $\mathrm{J}$ Rheumatol Suppl. 2014; 91: 56-64.

60. Documento congiunto Oms Europa-Ecdc. Tuberculosis surveillance and monitoring in $\mathrm{Eu}-$ rope 2018. ISBN 978-92-9498-174-5.

61. Lok AS, McMahon BJ. Chronic hepatitis B. Hepatology 2007; 45: 507-39.

62. Lok AS, McMahon BJ. Chronic hepatitis B: update 2009. Hepatology 2009; 50: 661-2.

63. Thong BY, Koh ET, Chng HH, Chow WC. Outcomes of chronic hepatitis B infection in Oriental patients with rheumatic diseases. Ann Acad Med Singapore. 2007; 36: 100-5.

64. Lan JL, Chen YM, Hsieh TY, et al. Kinetics of viral loads and risk of hepatitis B virus reactivation in hepatitis B core antibody-positive rheumatoid arthritis patients undergoing antitumour necrosis factor a therapy. Ann Rheum Dis. 2011; 70: 1719-25.

65. Kim PS, Ho GY, Prete PE, Furst DE. Safety and efficacy of abatacept in eight rheumatoid arthritis patients with chronic hepatitis B. Arthritis Care Res (Hoboken). 2012; 64: 1265-8.

66. Tamori A, Koike T, Goto H, et al. Prospective study of reactivation of hepatitis $B$ virus in patients with rheumatoid arthritis who received immunosuppressive therapy: evaluation of both HBsAg-positive and HBsAg-negative cohorts. J Gastroenterol. 2011; 46: 556-64.

67. Roux CH, Brocq O, Breuil V, et al. Safety of anti-TNF-a therapy in rheumatoid arthritis and spondylarthropathies with concurrent $\mathrm{B}$ or $\mathrm{C}$ chronic hepatitis. Rheumatology (Oxford). 2006; 45: 1294-7.

68. Li S, Kaur PP, Chan V, Berney S. Use of tumor necrosis factor- $\alpha$ (TNF- $\alpha$ ) antagonists infliximab, etanercept, and adalimumab in patients with concurrent rheumatoid arthritis and hepatitis B or hepatitis C: a retrospective record review of 11 patients. Clin Rheumatol. 2009; 28: 787-91.

69. Howick J, Chalmers I, Glasziou P, et al. The Oxford 2011 Levels of Evidence. Oxford Centre for Evidence-Based Medicine. Available from: http://www.cebm.net/index. aspx?o=5653

70. Burton MJ, Curtis JR, Yang S, et al. Safety of biologic and nonbiologic disease-modifying antirheumatic drug therapy in veterans with rheumatoid arthritis and hepatitis B virus infection: a retrospective cohort study. Arthritis Res Ther. 2015; 17: 136.

71. Varache S, Narbonne V, Jousse-Joulin S, et al. Is routine viral screening useful in patients with recent-onset polyarthritis of a duration of at least 6 weeks? Results from a nationwide longitudinal prospective cohort study. Arthritis Care Res. 2011; 63: 1565-70. 
72. Yeo W, Johnson PJ. Diagnosis, prevention and management of hepatitis $\mathrm{B}$ virus reactivation during anticancer therapy. Hepatology. 2006; 43: 209-20.

73. Lok AS, Liang RH, Chiu EK, et al. Reactivation of hepatitis $B$ virus replication in patients receiving cytotoxic therapy: report of a prospective study. Gastroenterology. 1991; 100: 182-8.

74. Huang YH, Hsiao LT, Hong YC, et al. Randomized controlled trial of entecavir prophylaxis for rituximab-associated hepatitis B virus reactivation in patients with lymphoma and resolved hepatitis B. J Clin Oncol. 2013; 31: 2765-72.

75. Evens AM, Jovanovic BD, Su YC, et al. Rituximab-associated hepatitis B virus (HBV) reactivation in lymphoproliferative diseases: metaanalysis and examination of FDA safety reports. Ann Oncol. 2011; 22: 1170-80.

76. Hsu C, Hsiung CA, Su IJ, et al. A revisit of prophylactic lamivudine for chemotherapy associated hepatitis $\mathrm{B}$ reactivation in nonHodgkin's lymphoma: a randomized trial. Hepatology. 2008; 47: 844-53.

77. Jang JW, Choi JY, Bae SH, et al. A randomized controlled study of preemptive lamivudine in patients receiving transarterial chemo-lipiodolization. Hepatology. 2006; 43: 233-40.

78. Lau GK, Yiu HH, Fong DY, et al. Early is superior to deferred preemptive lamivudine therapy for hepatitis B patients undergoing chemotherapy. Gastroenterology. 2003; 125: 1742-9.

79. Perez-Alvarez R, Diaz-Lagares C, GarciaHernandez F, et al. Hepatitis B virus (HBV) reactivation in patients receiving tumor necrosis factor (TNF)-targeted therapy: analysis of 257 cases. Medicine (Baltimore). 2011; 90: 359-71.

80. Hwang JP, Lok AS. Management of patients with hepatitis B who require immunosuppressive therapy. Nat Rev Gastroenterol Hepatol. 2014; 11: 209-19.

81. European Association for the Study of the Liver. EASL Clinical Practice Guidelines: Management of chronic hepatitis B virus infection. J Hepatol. 2012; 57: 167-85.

82. Lunel-Fabiani F, Masson C, Ducancelle A. Systemic diseases and biotherapies: Understanding, evaluating, and preventing the risk of hepatitis B reactivation. Joint Bone Spine. 2014; 81: 478-84.

83. Perrillo RP, Gish R, Falck-Ytter YT. American Gastroenterological Association Institute technical review on prevention and treatment of hepatitis B virus reactivation during immunosuppressive drug therapy. Gastroenterology. 2015; 148: 221-44.

84. Raimondo G, Allain J-P, Brunetto MR, et al. Statements from the Taormina expert meeting on occult hepatitis B virus infection. J Hepatol. 2008; 49: 652-7.

85. Li S, Kaur PP, Chan V, Berney S. Use of tumor necrosis factor- $\alpha(\mathrm{TNF}-\alpha)$ antagonists infliximab, etanercept, and adalimumab in patients with concurrent rheumatoid arthritis and hepatitis B or hepatitis C: a retrospective record review of 11 patients. Clin Rheumatol. 2009; 28: 787-91.

86. Pompili M, Biolato M, Miele L, Grieco A. Tumor necrosis factor-a inhibitors and chronic hepatitis C: a comprehensive literature review. World J Gastroenterol. 2013; 19: 7867-73.

87. Lin MV, Blonski W, Buchner AM, Reddy KR, Lichtenstein GR. The influence of antiTNF therapy on the course of chronic hepatitis $\mathrm{C}$ virus infection in patients with inflammatory bowel disease. Dig Dis Sci. 2013; 58: 1149-56.

88. Marotte H, Fontanges E, Bailly F, et al. Etanercept treatment for three months is safe in patients with rheumatological manifestations associated with hepatitis C virus. Rheumatology (Oxford). 2007; 46: 97-9.

89. Zein NN. Etanercept as an adjuvant to interferon and ribavirin in treatment-naive patients with chronic hepatitis $\mathrm{C}$ virus infection: a phase 2 randomized, double-blind, placebo- controlled study. J Hepatol. 2005; 42: 315-22.

90. Terrier B, Saadoun D, Sene D, et al. Efficacy and tolerability of rituximab with or without PEGylated interferon alfa-2b plus ribavirin in severe hepatitis $C$ virus-related vasculitis: a long-term follow up study of thirty-two patients. Arthritis Rheum. 2009; 60: 2531-40.

91. Iannone F, La Montagna G, Bagnato G, et al. Safety of etanercept and methotrexate in patients with rheumatoid arthritis and hepatitis $\mathrm{C}$ virus infection: a multicenter randomized clinical trial. J Rheumatol. 2014; 41: 286-92.

92. Ferri C, Ferraccioli G, Ferrari D, et al. Safety of anti-tumor necrosis factor-a therapy in patients with rheumatoid arthritis and chronic hepatitis C virus infection. J Rheumatol. 2008; 35: 1944-9.

93. Peterson JR, Hsu FC, Simkin PA, Wener MH. Effect of tumour necrosis factor a antagonists on serum transaminases and viraemia in patients with rheumatoid arthritis and chronic hepatitis $\mathrm{C}$ infection. Ann Rheum Dis. 2003; 62: 1078-82.

94. Parke FA, Reveille JD. Anti-tumor necrosis factor agents for rheumatoid arthritis in the setting of chronic hepatitis $\mathrm{C}$ infection. Arthritis Rheum. 2004; 51: 800-4.

95. Cavazzana I, Ceribelli A, Cattaneo R, Franceschini F. Treatment with etanercept in six patients with chronic hepatitis $\mathrm{C}$ infection and systemic autoimmune diseases. Autoimmun Rev. 2008; 8: 104-6. 
96. Cansu DU, Kalifoglu T, Korkmaz C. Shortterm course of chronic hepatitis B and C under treatment with etanercept associated with different disease-modifying antirheumatic drugs without antiviral prophylaxis. J Rheumatol. 2008; 35: 421-4.

97. Coppola N, Pisaturo M, Guastafierro S, et al. Increased hepatitis $\mathrm{C}$ viral load and reactivation of liver disease in HCV RNA positive patients with onco-haematological disease undergoing chemotherapy. Dig Liver Dis. 2012; 44: 49-54.

98. Cacoub P, Commarmond C, Sadoun D, Desbols AC. Hepatitis C virus infection and rheumatic diseases: the impact of direct-acting antiviral agents. Rheum Dis Clin North Am. 2017; 43: 123-32.

99. Ray KK, Kastelein JJ, Boekholdt SM, et al. The ACC/AHA 2013 guideline on the treatment of blood cholesterol to reduce atherosclerotic cardiovascular disease risk in adults: the good the bad and the uncertain: a comparison with ESC/EAS guidelines for the management of dyslipidaemias 2011. Eur Heart J. 2014; 35: 960-8.

100. Conroy RM, Pyörälä K, Fitzgerald AP, et al. Estimation of ten-year risk of fatal cardiovascular disease in Europe: the SCORE project. Eur Heart J. 2003; 24:987-1003.

101. Hollan I, Dessein PH, Ronda N, et al. Prevention of cardiovascular disease in rheumatoid arthritis. Autoimmun Rev. 2015; 14: 952-69.

102. Hippisley-Cox J, Coupland C, Vinogradova $\mathrm{Y}$, et al. Predicting cardiovascular risk in England and Wales: prospective derivation and validation of QRISK2. BMJ. 2008; 336: 1475-82.

103. Solomon DH, Greenberg J, Curtis JR, et al. Derivation and internal validation of an expanded cardiovascular risk prediction score for rheumatoid arthritis: a Consortium of Rheumatology Researchers of North America Registry Study. Arthritis Rheumatol. 2015; 67: 1995-2003.

104. Piepoli MF, Hoes AW, Agewall S, et al. 2016 European guidelines on cardiovascular disease prevention in clinical practice: the Sixth Joint Task Force of the European Society of Cardiology and Other Societies on Cardiovascular Disease Prevention in Clinical Practice (constituted by representatives of 10 societies and by invited experts) Developed with the special contribution of the European Association for Cardiovascular Prevention and Rehabilitation (EACPR). Eur Heart J. 2016; 37: 2315-81.

105. Wiersma T, Smulders YM, Stehouwer CD, et al. Summary of the multidisciplinary guideline on cardiovascular risk management (revision 2011). Ned Tijdschr Geneeskd. 2012; 156: A5104.
106. Mann DL, McMurray JJ, Packer M, et al. Targeted anticytokine therapy in patients with chronic heart failure: results of the Randomized Etanercept Worldwide Evaluation (RENEWAL). Circulation. 2004; 109: 1594-602.

107. Chung ES, Packer M, Lo KH, et al. Randomized, double-blind, placebo-controlled, pilot trial of infliximab, a chimeric monoclonal antibody to tumor necrosis factor a, in patients with moderate-to-severe heart failure: results of the Anti-TNF Therapy Against Congestive Heart Failure (ATTACH) trial. Circulation. 2003; 107: 3133-40.

108. Roubille C, Richer V, Starnino T, et al. The effects of tumour necrosis factor inhibitors, methotrexate, non-steroidal anti-inflammatory drugs and corticosteroids on cardiovascular events in rheumatoid arthritis, psoriasis and psoriatic arthritis: a systematic review and meta-analysis. Ann Rheum Dis. 2015; 74: 480-9.

109. Pharmacovigilance Risk Assessment Committee (PRAC). New safety advice for diclofenac - CMDh endorses PRAC recommendation. Available from: http://www.ema.europa.eu/ema/index.jsp?curl=pages/news_and_ events/news/2013/06/news_detail_001830. jsp\&mid $=$ WCOb01ac058004d5c 1

110. Pharmacovigilance Risk Assessment Committee (PRAC). PRAC recommends updating advice on use of high-dose ibuprofen. Available from: http://www.ema.europa. eu/ema/index.jsp?curl=pages/news_and_ events/news/2015/04/news_detail_002306. jsp\&mid=WC0b01ac058004d5c1

111. Lindhardsen J, Gislason GH, Jacobsen S, et al. Non-steroidal anti-inflammatory drugs and risk of cardiovascular disease in patients with rheumatoid arthritis: a nationwide cohort study. Ann Rheum Dis. 2013; 2013.

112. Ajeganova S, Svensson B, Hafström I. Low-dose prednisolone treatment of early rheumatoid arthritis and late cardiovascular outcome and survival: 10-year follow-up of a 2-year randomised trial. BMJ Open. 2014; 4: e004259.

113. Aviña-Zubieta JA, Abrahamowicz M, De Vera MA, et al. Immediate and past cumulative effects of oral glucocorticoids on the risk of acute myocardial infarction in rheumatoid arthritis: a population-based study. Rheumatology (Oxford). 2013; 52: 68-75.

114. Duru N, van der Goes MC, Jacobs JW, et al. EULAR evidence-based and consensusbased recommendations on the management of medium to high-dose glucocorticoid therapy in rheumatic diseases. Ann Rheum Dis. 2013; 72: 1905-13.

115. Innala L, Möller B, Ljung L, et al. Cardiovascular events in early RA are a result of inflammatory burden and traditional risk fac- 
tors: a five year prospective study. Arthritis Res Ther. 2011; 13: R131.

116. Chatterjee S, Sarkate P, Ghosh S. Early, structured disease modifying anti-rheumatic drug (DMARD) therapy reduces cardiovascular risk in rheumatoid arthritis - a single centre study using non-biologic drugs. J Assoc Physicians India. 2013; 61: 531-4.

117. Rao VU, Pavlov A, Klearman M, et al. An evaluation of risk factors for major adverse cardiovascular events during tocilizumab therapy. Arthritis Rheumatol. 2015; 67: 372-80.

118. Benucci M, Saviola G, Manfredi M, et al. Factors correlated with improvement of endothelial dysfunction during rituximab therapy in patients with rheumatoid arthritis. Biologics. 2013; 7: 69-75.

119. Kerekes G, Soltész P, Dér H, et al. Effects of rituximab treatment on endothelial dysfunction, carotid atherosclerosis, and lipid profile in rheumatoid arthritis. Clin Rheumatol. 2009; 28: 705-10.

120. Kume K, Amano K, Yamada S, et al. Tocilizumab monotherapy reduces arterial stiffness as effectively as etanercept or adalimumab monotherapy in rheumatoid arthritis: an open-label randomized controlled trial. J Rheumatol. 2011; 38: 2169-71.

121. Kang EH, Jin Y, Brill G, et al. Comparative cardiovascular risk of abatacept and tumor necrosis factor inhibitors in patients with rheumatoid arthritis with and without diabetes mellitus: a multidatabase cohort study. J Am Heart Assoc. 2018 [Epub ahead of print].

122. Kang EH, Liao KP, Kim SC. Cardiovascular safety of biologics and JAK inhibitors in patients with rheumatoid arthritis. Curr Rheumatol Rep. 2018; 20: 42.

123. Charles-Schoeman C, Wicker P, GonzalezGay MA, et al. Cardiovascular safety findings in patients with rheumatoid arthritis treated with tofacitinib, an oral Janus kinase inhibitor. Semin Arthritis Rheum. 2016; 46: 261-71.

124. Raaschou P, Simard JF, Holmqvist M, Askling J. Rheumatoid arthritis, anti-tumour necrosis factor therapy, and risk of malignant melanoma: nationwide population-based prospective cohort study from Sweden. BMJ. 2013; 346: f1939.

125. Dixon WG, Watson KD, Lunt M, et al.; on behalf of the British Society for Rheumatology Biologics Register. Influence of antitumor necrosis factor therapy on cancer incidence in patients with rheumatoid arthritis who have had a prior malignancy: results from the British Society for Rheumatology Biologics Register. Arthritis Care Res (Hoboken). 2010; 62: 755-63.
126. Kameda T, Dobashi H, Miyatake N, et al. Association of higher methotrexate dose with lymphoproliferative disease onset in rheumatoid arthritis patients. Arthritis Care Res (Hoboken). 2014; 66: 1302-9.

127. Mercer LK, Askling J, Raaschou P, et al. Risk of invasive melanoma in patients with rheumatoid arthritis treated with biologics: results from a collaborative project of $11 \mathrm{Eu}-$ ropean biologic registers. Ann Rheum Dis. 2017; 76: 386-91.

128. Hodi FS, O’Day SJ, McDermott DF, et al. Improved survival with ipilimumab in patients with metastatic melanoma. $\mathrm{N}$ Engl J Med. 2010; 363: 711-23.

129. Topalian SL, Hodi FS, Brahmer JR. Safety, activity, and immune correlates of anti-PD-1 antibody in cancer. N Engl J Med. 2012; 366: 2443-54.

130. Belkhir R, Burel SL, Dunogeant L, et al. Rheumatoid arthritis and polymyalgia rheumatica occurring after immune checkpoint inhibitor treatment. Ann Rheum Dis. 2017; 76: 1747-50.

131. Winthrop KL. The emerging safety profile of JAK inhibitors in rheumatic disease. Nat Rev Rheumatol. 2017; 13: 234-43. Erratum in: Nat Rev Rheumatol. 2017; 13: 320.

132. Zhang J, Xie F, Delzell E, et al. Association between vaccination for herpes zoster and risk of herpes zoster infection among older patients with selected immune-mediated diseases. JAMA. 2012; 308: 43-9.

133. Zhang J, Delzell E, Xie F, et al. The use, safety, and effectiveness of herpes zoster vaccination in individuals with inflammatory and autoimmune diseases: a longitudinal observational study. Arthritis Res Ther. 2011; 13: R174.

134. Kaine JL, Kivitz AJ, Birbara C, Luo AY. Immune responses following administration of influenza and pneumococcal vaccines to patients with rheumatoid arthritis receiving adalimumab. J Rheumatol. 2007; 34: 272-9.

135. Visvanathan S, Keenan GF, Baker DG, et al. Response to pneumococcal vaccine in patients with early rheumatoid arthritis receiving infliximab plus methotrexate or methotrexate alone. J Rheumatol. 2007; 34: 952-7.

136. Mease PJ, Ritchlin CT, Martin RW, et al. Pneumococcal vaccine response in psoriatic arthritis patients during treatment with etanercept. J Rheumatol. 2004; 31: 1356-61.

137. Coulson E, Saravanan V, Hamilton J, et al. Pneumococcal antibody levels after pneumovax in patients with rheumatoid arthritis on methotrexate. Ann Rheum Dis. 2011; 70: 1289-91.

138. Kapetanovic MC, Roseman C, Jonsson G, et al. Antibody response is reduced following vaccination with 7-valent conjugate pneumo- 
coccal vaccine in adult methotrexate-treated patients with established arthritis, but not those treated with tumor necrosis factor inhibitors. Arthritis Rheum. 2011; 63: 3723-32.

139. Kapetanovic MC, Saxne T, Sjoholm A, et al. Influence of methotrexate, TNF blockers and prednisolone on antibody responses to pneumococcal polysaccharide vaccine in patients with rheumatoid arthritis. Rheumatology (Oxford). 2006; 45: 106-11.

140. Elkayam O, Caspi D, Reitblatt T, et al. The effect of tumor necrosis factor blockade on the response to pneumococcal vaccination in patients with rheumatoid arthritis and ankylosing spondylitis. Semin Arthritis Rheum. 2004; 33: 283-8.

141. Kim DK, Bridges CB, Harriman KH. Advisory Committee on Immunization Practices recommended immunization schedule for adults aged 19 years or older: United States, 2015. Ann Intern Med. 2015; 162: 214-23.

142. Kim DK, Bridges CB, Harriman KH. Advisory Committee on Immunization Practices recommended immunization schedule for adults aged 19 years or older, United States, 2015. MMWR Morb Mortal Wkly Rep. 2015; 64: 91-2.

143. US Department of Health and Human Services. Centers for Disease Control and Prevention. Recommended adult immunization schedule, United States 2014. Available from: http://www.cdc.gov/vaccines/schedules/downloads/adult/adultschedule.pdf

144. National Center for Immunization and Respiratory Diseases. General recommendations on immunization: recommendations of the Advisory Committee on Immunization Practices (ACIP). MMWR Recomm Rep. 2011; 60: 1-64.

145. Advisory Committee on Immunization Practices. ACIP Recommendations: 2014. Immunization Action Coalition. Available from: http://www.immunize.org/acip/acip_2014. asp

146. Bingham CO III, Looney RJ, Deodhar A, et al. Immunization responses in rheumatoid arthritis patients treated with rituximab: results from a controlled clinical trial. Arthritis Rheum. 2010; 62: 64-74.

147. Winthrop KL, Silverfield J, Racewicz A, et al. The effect of tofacitinib on pneumococcal and influenza vaccine responses in rheumatoid arthritis. Ann Rheum Dis. 2016; 75 : 687-95.

148. Götestam Skorpen C, Hoeltzenbein M, Tincani A, et al. The EULAR points to consider for use antirheumatic drugs before pregnancy, during pregnancy and lactation. Ann Rheum Dis. 2016; 75: 795-810.

149. CIMZIA ${ }^{\circledR}$ Riassunto delle Caratteristiche di Prodotto (agg.19/07/2018).
150. Mariette X, Förger F, Abraham B, et al. Lack of placental transfer of certolizumab pegol during pregnancy: results from CRIB, a prospective, postmarketing, pharmacokinetic study. Ann Rheum Dis. 2018; 77: 228-33.

151. Clowse ME, Förger F, Hwang C, Thorp J, Dolhain RJ, van Tubergen A et al. Minimal to no transfer of certolizumab pegol into breast milk: results from CRADLE, a prospective, postmarketing, multicentre, pharmacokinetic study. Ann Rheum Dis. 2017; 76: 1890-6.

152. Verschueren P, De Cock D, Corluy L, et al. Methotrexate in combination with other DMARDs is not superior to methotrexate alone for remission induction with moderate-to-high-dose glucocorticoid bridging in early rheumatoid arthritis after 16 weeks of treatment: the CareRA trial. Ann Rheum Dis. 2015; 74: 27-34.

153. Nam JL, Villeneuve E, Hensor EM, et al. Remission induction comparing infliximab and high-dose intravenous steroid, followed by treat-to-target: a double-blind, randomised, controlled trial in new-onset, treatmentnaive, rheumatoid arthritis (the IDEA study). Ann Rheum Dis. 2014; 73:75-85.

154. Felson DT, Smolen JS, Wells G, et al. American College of Rheumatology/European League against Rheumatism provisional definition of remission in rheumatoid arthritis for clinical trials. Ann Rheum Dis. 2011; 70: 404-13.

155. Aletaha D, Landewé R, Karonitsch T, et al. Reporting disease activity in clinical trials of patients with rheumatoid arthritis: EULAR/ ACR collaborative recommendations. Ann Rheum Dis. 2008; 67: 1360-4.

156. van Sijl AM, Boers M, Voskuyl AE, Nurmohamed MT. Confounding by indication probably distorts the relationship between steroid use and cardiovascular disease in rheumatoid arthritis: results from a prospective cohort study. PLoS One. 2014; 9: e87965.

157. del Rincón I, Battafarano DF, Restrepo JF, et al. Glucocorticoid dose thresholds associated with all-cause and cardiovascular mortality in rheumatoid arthritis. Arthritis Rheumatol. 2014; 66: 264-72.

158. Dixon WG, Abrahamowicz M, Beauchamp ME, et al. Immediate and delayed impact of oral glucocorticoid therapy on risk of serious infection in older patients with rheumatoid arthritis: a nested case-control analysis. Ann Rheum Dis. 2012; 71: 1128-33.

159. Verschueren P, De Cock D, Corluy L, et al. Effectiveness of methotrexate with stepdown glucocorticoid remission induction (COBRA Slim) versus other intensive treatment strategies for early rheumatoid arthritis in a treat-to-target approach: 1-year 
results of CareRA, a randomised pragmatic open-label superiority trial. Ann Rheum Dis. 2017; 76: 511-20.

160. Negoescu AF, Östör AJ. Refining the management of rheumatoid arthritis: the benefits of subcutaneous tocilizumab. Rheumatol Ther. 2015; 2: 17-31.

161. Cohen SB, Tanaka Y, Mariette X, et al. Longterm safety of tofacitinib for the treatment of rheumatoid arthritis up to 8.5 years: integrated analysis of data from the global clinical trials. Ann Rheum Dis. 2017; 76: 1253-62.

162. Verden A, Dimbil M, Kyle R, et al. Analysis of spontaneous postmarket case reports submitted to the FDA regarding thromboembolic adverse events and JAK inhibitors. Drug Saf. 2018; 41: 357-361.

163. Smolen JS, Van Der Heijde DM, et al. Predictors of joint damage in patients with early rheumatoid arthritis treated with highdose methotrexate without or with concomitant infliximab: results from the ASPIRE trial. Arthritis Rheum. 2006; 54: 702-10.
164. van Leeuwen MA, van Rijswijk MH, Sluiter WJ, et al. Individual relationship between progression of radiological damage and the acute phase response in early rheumatoid arthritis. Towards development of a decision support system. J Rheumatol. 1997; 24: 20-7.

165. Van der Heijde DM, van Riel PL, van Leeuwen MA, et al. Prognostic factors for radiographic damage and physical disability in early rheumatoid arthritis. A prospective follow-up study of 147 patients. Br J Rheumatol. 1992; 31: 519-25.

166. Scott DL, Symmons DP, Coulton BL, Popert AJ. Long-term outcome of treating rheumatoid arthritis: results after 20 years. Lancet. 1987; 1: 1108-11.

167. Anderson J, Caplan L, Yazdany J, et al. Rheumatoid arthritis disease activity measures: American College of Rheumatology recommendations for use in clinical practice. Arthritis Care Res (Hoboken). 2012; 64: 640-7. 